Historic, Archive Document

Do not assume content reflects current scientific knowledge, policies, or practices. 

$.171 \%$

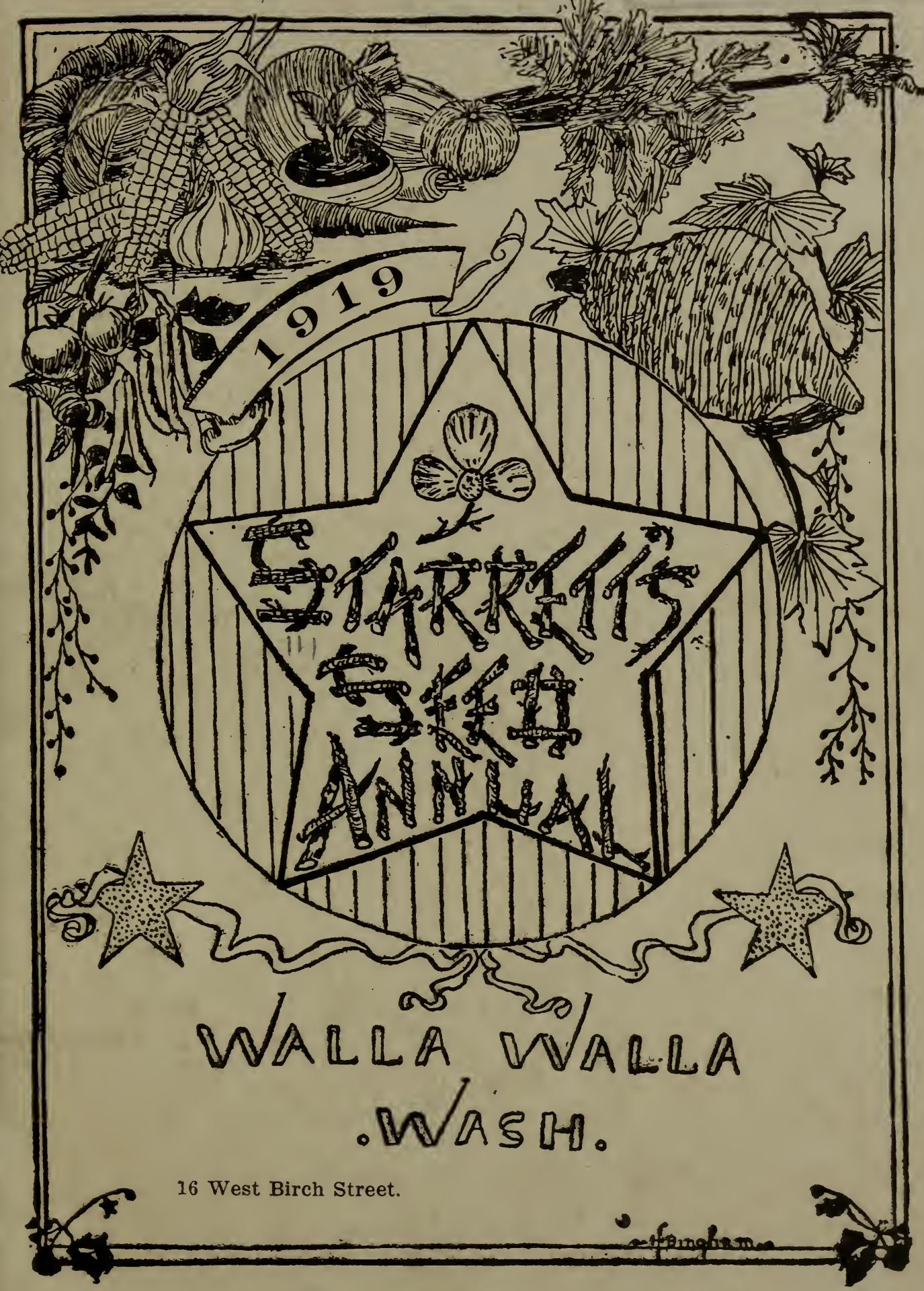




\section{PARCEL POST DIRECTIONS}

1st Zone 50 miles 1 pound 5 cents 2nd Zone 150 miles 1 pound 5 cents 3rd Zone 300 miles 1 pound 6 cents 4 th Zone 600 miles 1 pound 7 cents 5 th Zone 1000 miles 1 pound 8 cents 6th Zone 1400 miles 1 pound 9 cents 7th Zone 1800 miles 1 pound 11 cents 8 th Zone 3000 over 1 pound 12 cents
Each extra pound 1 cent Each extra pound 1 cent Each extra pound 2 cents Each extra pound 4 cents Each extra pound 6 cents Each extra pound 8 cents Each extra pound 10 cents Each extra pound 12 cents 


\section{Starrett's \\ 45th Annual Catalogue of Northern Grown Seed}

As the season of 1909 is at hand, I take pleasure in presenting you my Seed Annual, that you may look over your requirements for the coming season. While my catalogue is not flowery or elaborate, still I list well tried sorts of merit that will give results, which is what most people are looking for. The demand for produce will be steadily increasing since the war is over and the soldiers come marching home to take their places in the development of the country. You will notice higher prices prevail and no wonder; labor higher, rents and contracts higher, in fact commodities of all kinds are higher. Some seeds are very short and the question: will we be able to get enough for the demand? Grass seed is higher as the price of hay has kept the seed market bare. Wishing a share of your patronage which will have my best attention. Wishing you a Happy and Prosperous New Year, I am

Yours truly,

W. G. STARRETT. 



\section{Name and Address-}

We beg our correspondents to gire us very exactly ON EACH OF THEIR ORDERS THEIR NAME AND ADDRESS, also to indicate, VERY PRECISELY, the means of carriage which they prefer, whether by express, freight or mail, and the postoffice or railroad station which best serves their locality. In case these directions are not followed out, or if the directions given are not sufficient, we will choose ourselres the most conrenient means, but entirely at the risk of the customer.

\section{REMITTANCES.}

When ordering, please send remittances at the same time, and if I receive the money, I guarantee the safe arrival of all packages. Money can safely be sent by postoffice money order, express order, registered letter or Portland exchange. Amounts less than one dollar can be sent in 5-cent and 10-cent stamps. Goods will be sent to the amount of remittance only. No goods sent C. O. D. unless one-half the amount of the price accompanies the order.

\section{SEEDS BY MAIL.}

All seeds sent postage paid, at prices named in this catalogue, except grass and tree seeds, corn, beans and peas, and sets, for which postage must be sent. If this is omitted, postage will be deducted from amount sent.

\section{TO MARKET GARDNERS.}

Market gardeners, or those desiring to plant largely, will please write for special prices and they are earnestly requested to send their orders early. If you will mail a list of seeds desired, I will promptly return it with lowest prices for same.

We want our customers to understand that their orders, large or small. will have prompt, careful attention.

We would be pleased to mail our catalogue to any of your friends who may need seeds, and will cheerfully do so if you will kindly send their names

We wish to call attention to the descriptions and directions giren in this catalogue concerning each rariety of seeds and their culture. They are as full and explicit as the limited space will permit, and are worthy of reference. 



\section{VEGETABLE SEED}

Please note that our prices include payment of postage on all garden seeds except beans; corn and peas, for which postage must accompany the order if to go by mail.

\section{ASPARAGUS.}

CULTURE.-Soak the seeds in tepid water about one week before planting. Sow thinly in rows about one foot apart and keep clean from weeds. When plants are one year old, plant out in well manured soil; if for private

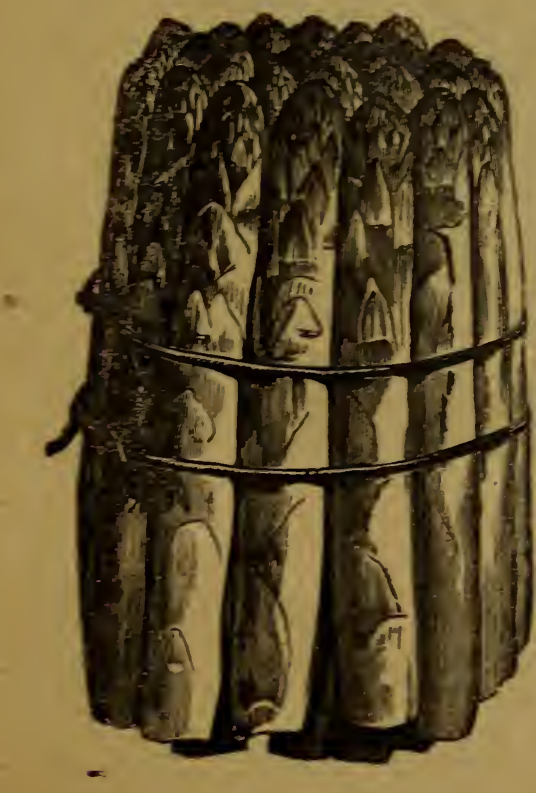
garden, set in rows about eighteen inches apart each way. For market, planted on a large scale, set in rows four feet apart and eighteen inches in the row. Top dress with manure every fall.

COLLOSAL.-The old standard sort; and largely planted. Seeds per ounce, 10c; $1 / 4$ tb. $25 \mathrm{c}$, tb. $75 \mathrm{c}$.

COLUMBIA MAMMOTH WHITE,-A distinct variety of strong vigorous growth, producing very large white shoots, that in favorable weather remain white as long as fit for use. Pkg. $71 / 2 \mathrm{c}$; oz. $15 \mathrm{c} ; 1 / 4$ th. $25 \mathrm{c}$; it. $75 \mathrm{c}$.

PALMETTO.-This variety is of southern origin; rery desirable on account of its earliness, bright green color, presenting an attractive appearance, excellent flavor, and productiveness. Seeds, per oz. 15c; $1 / 4$ to. $25 \mathrm{c} ;$ tb. $75 \mathrm{c}$. 
BEANS.

In ordering add Parcel Postage.

CULTIVATION.-Mark out furrows about four inches deep, two and one-half feet apart for the smaller and three feet for the strong growing varieties, and plant from three to six inches apart in the rows, according to variety. One and one-half bushels will plant an acre. The season to plant varies with location, of course, but a safe guide is to plant when the apple is in blossom; then at intervals as desired. "Pickling beans," used for salting. down for winter, may be planted about the first week in July. For this purpose Refugee is principally grown.

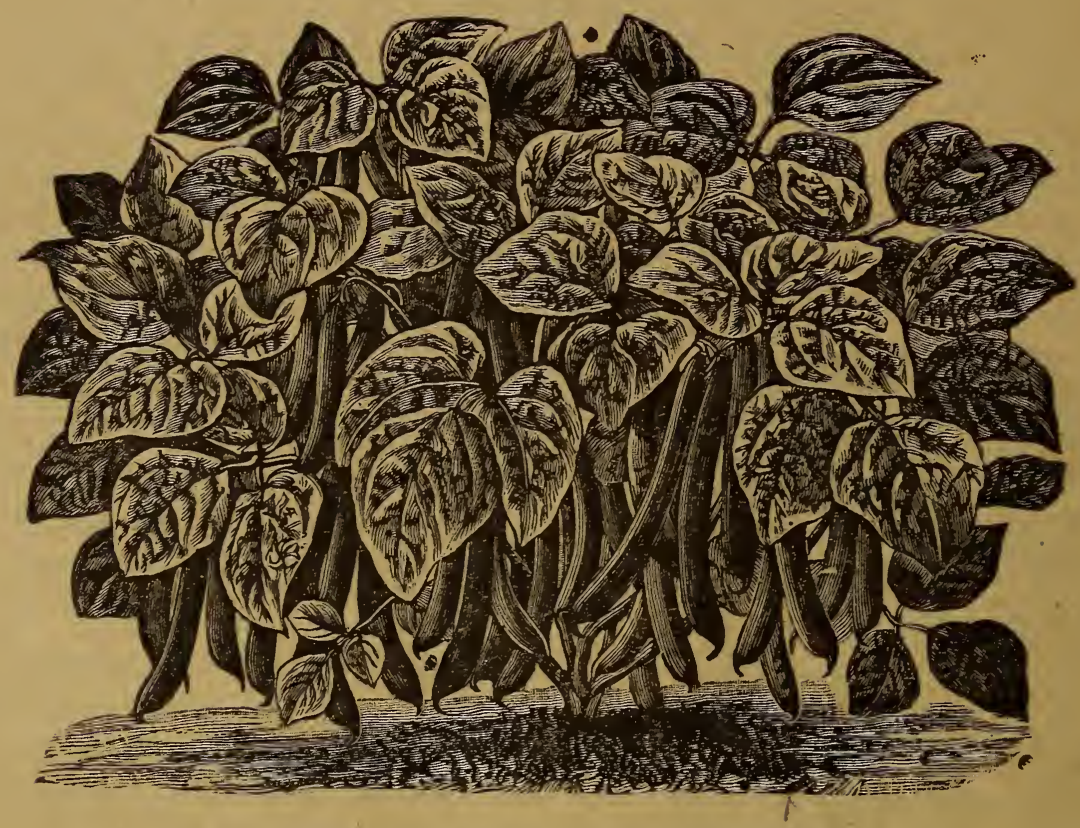

BURPEE'S NEW STRINGLESS GREEN POD.-Is the bean which in the opinion of many growers, is destined to replace the Valentine. Leads the Valentine by about two weeks in earliness; pods longer, straighter, and fully as round and fleshy. Distinguished from all other green podded sorts by its absolute freedom from strings. Per tb. $30 \mathrm{c}$.

IMPROVED REFUGEE.-Large, productive, hardy, tender, fleshy pods, a great improvement on the old Refugee. Per tb. $30 \mathrm{c}$. 
EXTRA EARLY RED VALENTINE.-Pods develop to an edible condition in thirty-two days from germination. Color of pods light green; succulent, prolific and quite free from strings, continuing long in an edible condition. Per Ib. 35c.

IMPROVED BLACK, OR GERMAN WAX.-Earlier than the old sort; the lods are larger, round, full, and entirely stringless. Per To. $35 \mathrm{c}$.

NEW DAVIS WAX.-Pods are very waxy-white, long, straight and thick. Beans clear, white, kidney-shaped. Very productive. Compact, upright growth. Per Tb. 35c.

GOLDEN WAX.-The old familiar variety; more largely grown in private gardens than any other. Ped Tb. $35 \mathrm{c}$.

BURPEE'S DWARF LIMA.-Beans as large as the Large Pole Lima, but strictly dwarf, and come absolutely true from seed. Of stout growth and always erect, branching vigorously, bearing from fifty to two hundred handsome, large pods, well filled with very large beans, identical in size and luscious flavor to the well known Large Pole Limas. Per to. $35 \mathrm{c}$.

BROAD WINSOR.-Strong and shrubby stock erect; the bean is large, broad and flat; it is the best used as a shell bean. Per th., 25c.

POLE BEANS.

LAZY WIVE.-Pods are very broad, thick, fleshy and entirely stringless; they retain their excellent qualities until almost ripe, and are immensely productive. Per Ib. $35 \mathrm{c}$.

CREASEBACK, OR FAT-HORSE BEAN.-The earliest pole bean in cultiration, exceedingly productive and of the finest quality. Per $\mathrm{tb} .35 \mathrm{c}$.

KENTUCKY WONDER.-A very prolific sort, bearing its pods in large clusters; pods green, often reaching nine or ten inches in length, nearly round when young, and very crisp. Per ib. $35 \mathrm{c}$. 


\section{BEETS.}

Sow as early in the spring as the ground can be worked for early, and any time to first week in July. For early crop the soil should be light, sandy loam, well manured, plowed and harrowed fine. Sowed in drills fifteen to eighteen inches apart and thin to about six inches. The Mangel Wurzel and Sugar Beets may be planted first of May to first of June in rows eighteen to twenty-four inches apart, and thin to eight inches in the row. Of either variety about four pounds of seed to the acre is required.

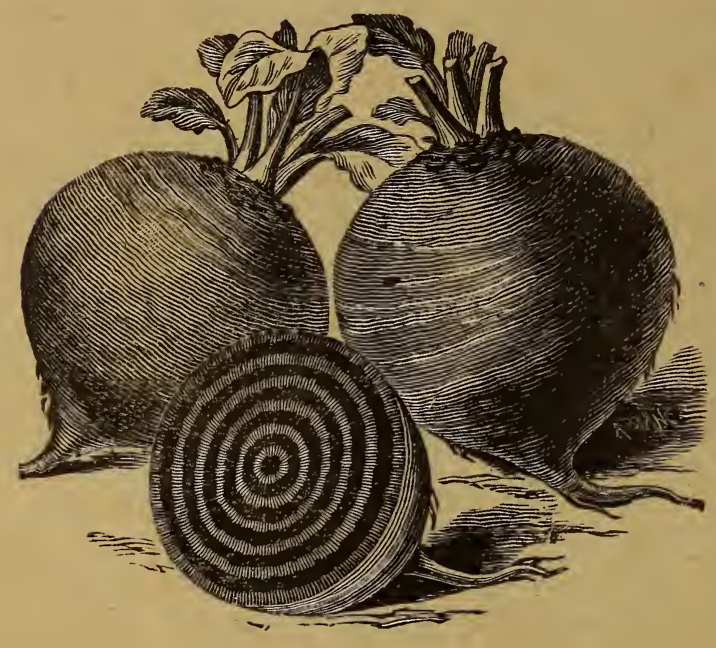

MARKET GARDENERS':This is the ideal "market gardener's" beet. It is very symmetrical, with small tap roots and but a few fibrous roots. It is about as early as Egyption, handsome and of much better quality, cooking sweet and tender, of deep rich color. Lb. $\$ 1.60$; $1 / 4$ tb., 50c; oz., 15c; pkg., $5 c$.

EGYPTIAN. - A standard early sort, and extensively grown by both market gardeners and for private use. It is extra early, flat in shape with very small tap root; deep blood red, sweet and tender when young, but apt to tb., $\$ 1.60 ; 1 / 4 \cdot$ tb., $50 \mathrm{c}$; oz., $15 \mathrm{c}$; pkg. 5 c.

ECLIPSE.-Similar to Early Bassano in earliness, roots round and smooth, smooth, blood red skin and flesh, very desirable. Per Ib., $\$ 1.60 ; 1 / 4$ Ib., 50c; pkg. $7 \frac{1}{2}$ c.

EDMUND'S BLOOD TURNIP.-An improved strain of blood Turnip Beet that in some localities is grown to the exclusion of all others as a winter sort. It is globe-shaped, remarkably smooth with small tap root and very few fibrous roots. Per tb., $\$ 1.35 ; 1 / 4$ tb., $40 \mathrm{c}$; oz., $15 \mathrm{c}$; pkg., $71 / 2 \mathrm{c}$. 
BLOOD TURNIP-Known as "Turnip-rotten Blood," is an old standard variety that our mothers used to grow, and so far as quality is concerned, has never been excelled. Skin and flesh blood-red, cooking very sweet and tender. Per tb., $\$ 1.25 ; 1 / 1$ tb., $40 \mathrm{c} ;$ 0z., 10c; pkg., 71/2 c.

DETROIT DARK RED.-A grand turnip beet for second early crop; dark red all through; no white streaks, which often occur in other turnip beets. Price per to., $\$ 1.25 ; 1 / 4$ tb., $40 \mathrm{c}$; oz., $10 \mathrm{c} ; \mathrm{pkg}$., $71 \frac{1}{2} \mathrm{c}$.

GOLDEN TANKARD.-The best type of intermediate Mangold; small top, broad shoulder, smooth, rich skin, very solid flesh, golden stemmed. It admits of close culture and is a heary cropper. Per to. $\$ 1.00 ; 1 / 4$ to. $30 \mathrm{c}$; pkg., $71 / 2 \mathrm{c}$.

GIANT HALF.SUGAR.-One of the most valuable for feeding stock. It unites the large size of the mangel with the great feeting value of the sugar beet. Per Ib., $\$ 1.00$; $1 / 4$ tb., $30 \mathrm{c}$; oz., $15 \mathrm{c}$.

MAMMOTH LONG RED MANGEL WURZEL.-Very large and produc-

trie, generally grows one-half out of the ground. Per tb. $\$ 1.00 ; 1 / 4$ tb. $30 \mathrm{c}$; pkg., $71 / 2 \mathrm{c}$.

\section{BRUSSELS SPROUTS.}

A species of cabbage that produces minature heads from the sides of the stalk. These heads are a great delicacy boiled in the same way as cauliflower. The seed is sown about the middle of May in a seed bed, and afterwards set out in rows two feet apart, and cultivated the same as cabbage. This regetable does not require high cultivation, however. It is ready for use in late autumn after early frost. Per Tb., \$2.50; $1 / 4$ tb., 75c; oz., 25c; pkg.. $71 / 2 \mathrm{c}$.

\section{BROCCOLI.}

A favorite European regetable, nearly allied to the Cauliflower, but more harder and surer to head. The seed should be sown in early May and trans. planted in June, in short, treated as late cabbage. It succeeds better in a cold, heavy soil.

WHITE CAPE.-The variety most popularly and generally grown. Per oz., \$1.50; pkg., $71 / 2 \mathrm{C}$. 
BORECOLE, OR KALE.

One ounce of sed will produce about 3000 plants.

The cultivation is similar to cabbage. A strong soil, well manured, is required. Borecole is considered by some more delicate than cabbage when boiled, the quality being improved after a slight frost. That grown for early spring use should be sown about October 1st; a light sprinkle of straw may be applied late in the fall to prevent from severe freezing.

CURLED DWARF GREEN.-Vèry dwarf and spreading. Per tb., $\$ 2.00$; $1 / 4$. Ib., 75c; oz., 25c; pkg., $7 \frac{1}{2} \mathrm{c}$.

TALL SCOTCH.-Taller of growth requiring as much room as early cabbage. Per tb., $\$ 2.00 ; 1 / 2$ tb., $75 \mathrm{c}$; oz., $25 \mathrm{c}$; pkg., $7 \frac{112}{2} \mathrm{c}$.

\section{CABBAGE.}

An ounce of seed will produce about 3000 plants.

The manner of cultivation here given is that pursued by our most successful market gardeners, and can as well be applied in cultivating the family garden, always remembering, however, that good, early cabbage cannot be grown except in highly manured soil. For early crop seed is sown thinly in the open ground from the 10th to the 20th of September, not earlier nor later, and can be transplanted when large enough to handle nicely, in rows $21 / 2$ feet apart and 15 and 18 inches in the row, on land upon which cabbage has not been grown for at least one year, to avoid "club-root." In planting, care should be taken to place the plants deep enough to protect the stalk, and yet not deep enough to cover the bud.

Where fall planting is not practicable, plants can be had quite early in the spring by planting the seeds in a hot bed about the 1st to 10 th of February.

For late cabbage, seed should be sown from the 10th to 20 th of May, and transplanted when large enough to handle, say 4 to 5 inches high, into rows, three feet apart, and 2 feet in the row, except the very large growing sorts, which should be planted $4 \times 4$ feet. The varieties here given are the most approved sorts grown.

EXTRA EARLY EUREKA.-A cross between the Wakefield and Succession, as early as the Wakefield, heads round, of Succession type, and as hard as the Holland or Danish Ball Head. Per tb., $\$ 5.00 ; 1 / 4$ tb., $\$ 1.25$; oz., 50c; pkg. 10c.

JERSEY WAKEFIELD.-True stock.-This seed is grown in the usual way, allowing the side shoots to produce seed, hence the lower price. Per Ib., $\$ 5.00 ; 1 / 4$ tb., $\$ 1.25 ;$ oz., 50c; pkg., $10 \mathrm{c}$.

EARLY YORK.-This is very popular in the family garden and is largely grown as a first early; it is not popular with those growing for shipping purposes. Per tb., $\$ 5.00 ; 1 / 4$ tb., $\$ 1.25$; oz., 50c; pkg., $10 \mathrm{c}$. 


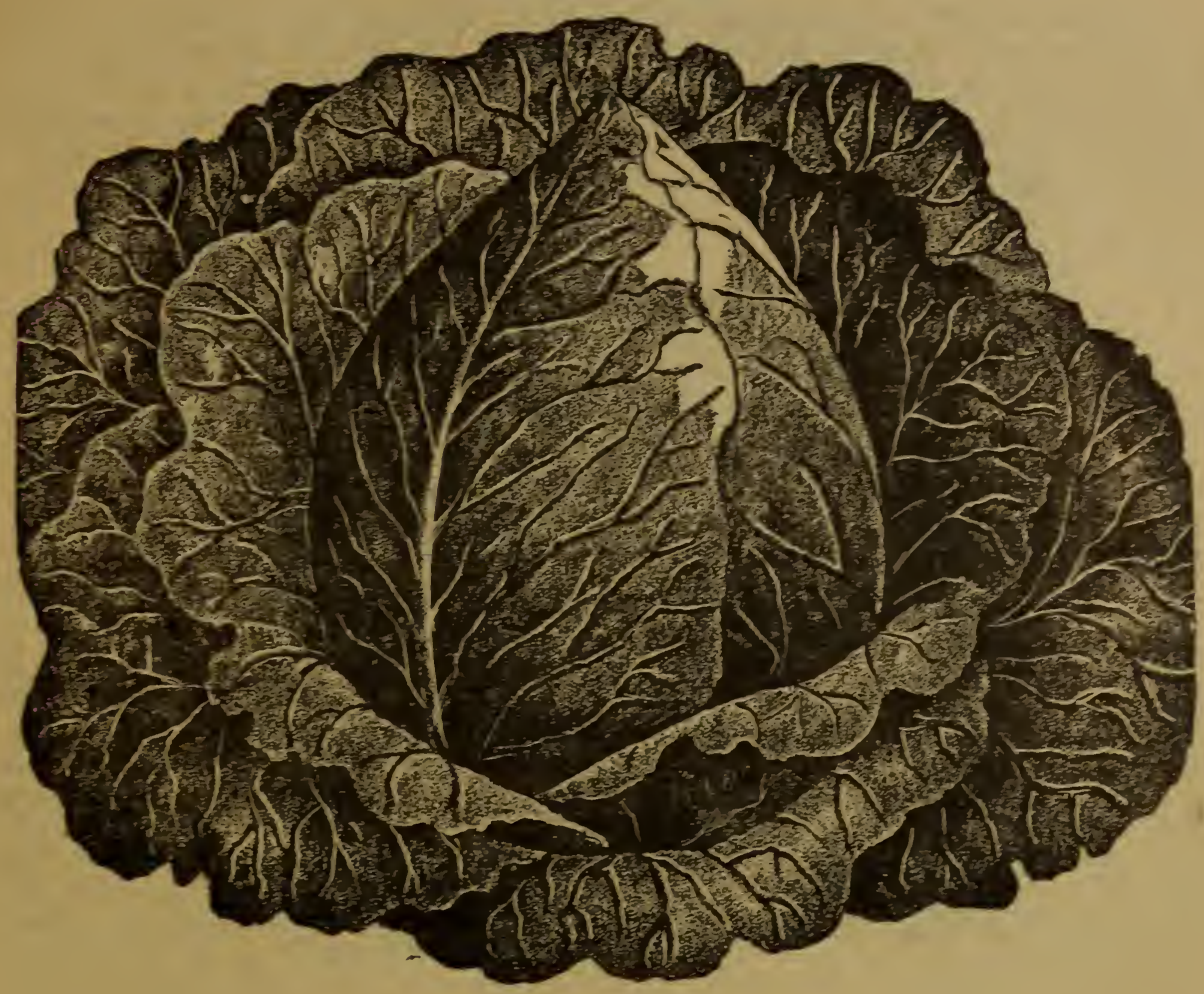

SELECT LARGE JERSEY WAKEFIELD.-This is the sort universally grown for main crop of early cabbage and the quality of the seed planted is of the greatest importance. The seed is grown from selected heads, and only the center shoot allowed to produce seed, all others being removed. This is known as market gardener's stock, and necessarily commands a high price. Per tb.. $\$ 4.00 ; 1 / 4$ th., $\$ 1.25 ;$ oz., 50 c; pkg., 1 f c.

EARLY WINNINGSTADT.-This sort follows the Oxheart and is an old favorite. It is what is known as a sugar-loaf variety, having a long, pointed head of remarkable solidity; is a sure header; grows to good size and does better in light soil than most varieties. Per th., $\$ 5.00 ; 1 / 4$ to., $\$ 1.25 ; 0 z ., 50 \mathrm{c}$; pkg., $10 \mathrm{c}$.

COPENHAGEN MARKET.-Without doubt the finest, largest round. headed cabbage in cultivation. The type is fixed and the heads mature all at the same time. The heads are large, averaging about 10 pounds; are very solid, and of fine flavor. It matures with the last of the Wakefield, making it a splendid second early cabhage. Per $\mathrm{ro} ., \$ 7.00 ; 1 / 4 \mathrm{~Tb} ., \$ 2.00 ; 0 \mathrm{z} ., 50 \mathrm{c}$. 
HENDERSON'S SUCCESSION.-True stock.-This Mr. Henderson considers his most valuable introduction, saying of it: "It is so finely bred and so true to type that in a field of twenty acres every head appears alike." It is like Brill's "None-such," an all-season variety, and is an equally valuable second early, or fall or winter sort, and a sure header. Per $1 \mathrm{~b} ., \$ 5.00 ; 1 / 4 \mathrm{tb}$., $\$ 1.25$; oz., $50 \mathrm{c}$; pkg., $10 \mathrm{c}$.

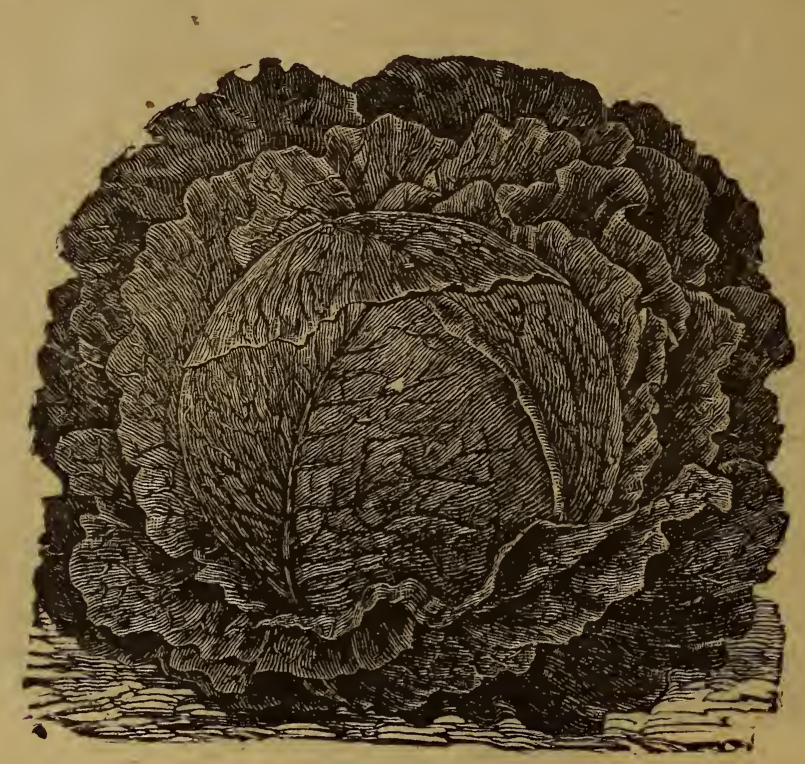

LOUISVILLE DRUMHEAD.-This is the finest strain of Drumhead Cabbage in existence, bright green foliage and short stem, heads large, round and thick; a sure header, will stand longer without bursting than any other variety. For winter use the seeds should be sown latter part of May. Per tb., $\$ 5.00 ; 1 / 4$ 1b., $\$ 1.25$; oz., 50c; pkg., $10 \mathrm{c}$.

DANISH BALLHEAD.-In Denmark a variety grown almost exclusively for wintr cabbage, and annually exported in large quantities. Has been selected for more than fifty years by Danish gardeners. Heads are hard, round, of good marketable size, fine grained and long keepers. Per tb., $\$ 5.00$; $1 / 4$ tb., $\$ 1.25$; oz., 50c; pkg., 10c.

LARGE LATE DRUMHEAD.-One of the largest, most solid and best keeping late sorts. Seeds should be sown about May 10, as it requires quite a long season to make a perfect, solid head. Per Ib., $\$ 5.00 ; 1 / 4$ tb., $\$ 1.25 ;$ oz., $50 \mathrm{c}$; pkg., $10 \mathrm{c}$.

EXCELSIOR FLAT DUTCH.-Selected stock.-A very popular and a highly esteemed variety; grows to large size, flat solid heads often weighing 15 to 20 pounds. A sure header and good keeper over winter; extensively grown for shipping purposes. Per 1b., $\$ 5.00$; 1/4 1b., $\$ 1.25$; oz., 50c; pkg., $10 \mathrm{c}$. 


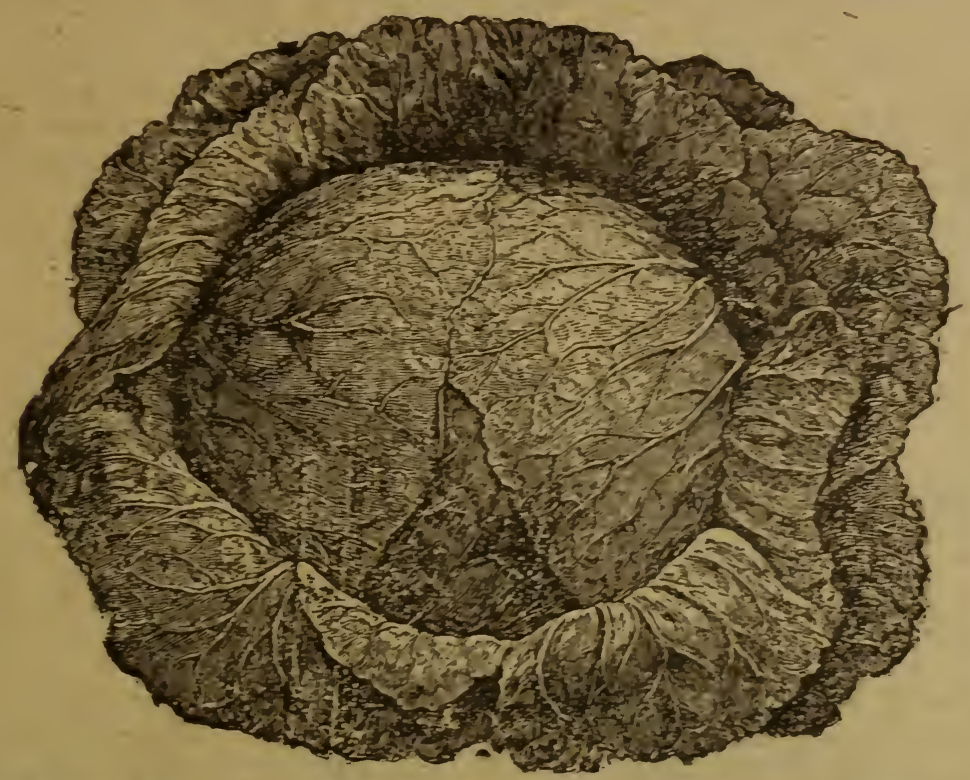

BURPEE'S WORLD BEATER CABBAGE.-This is an exceedingly large cabbage of the Drumbead variety. It has short, thick stalk, dark green foliage of a slight reddish hue; makes a very hard, solid head of immense proportions and extraordinary weight; a sure header. Usually large growing sorts are coarse; this, on the contrary, is one of excellent quality. It is too large for market except where sold by weight; fine for kraut or spring sales; one of the best keepers grown. Its season is late, and seeds should be planted, according to location, from April 15 th to May 10 th. Per Ib., $\$ 5.00 ; 1 / 41 \mathrm{tb} ., \$ 1.25$; $50 \mathrm{c}$; pkg., $10 \mathrm{c}$.

MAMMOTH MARBLE HEAD.-The largest of all cabbages, often grow. ing to weigh 30 to 40 pounds. It is not desirable, being coarse and rather strong when cooked, lacking the delicate flavor of the smaller sorts. Per lb. $\$ 2.50$; $1 / 4$ lb. $65 \mathrm{c}$; oz. $25 \mathrm{c}$; pkg. $5 \mathrm{c}$.

. PERFECTION DRUMHEAD SAVOY.-For winter use this variety is unsurpassed, closely resembling the Cauliflower in delicacy and delicious flavor. The best of all Savors for market or home use; short stem, heads are large, compact and solid; a sure header. Per tb., $\$ 7.00 ; 1 / 4$ tb., $\$ 2.00$; oz., $70 \mathrm{c}$; pkg., 10c.

RED DUTCH.-Use for pickling, for which purpose it is the best grown. Per lb. $\$ 2.50 ; 1 / 4$ lb. $65 \mathrm{c}$; oz. $25 \mathrm{c}$; pkg. $5 \mathrm{c}$.

\section{CAULIFLOWERS.}

Cauliflowers to be grown profitably, require a deep, strong, rich soll, highly manured, and upon which cabbage or turnips have not been grown the prevlous year. The great drawback to the successful cultivation of this regetable is our hot, dry weather, hence it is best to plant very early, give an abundance of manure, water freely, particularly when forming heads. The proper way would be to plant the seeds in the fall, the same as early cabbage, and winter the plants over in a cold frame. planting out in the spring as early as the ground can be worked. The seeds of the late sorts should not be planted earlier than June 1st. The cultiration is the same as for cabbage. 


\section{CAULIFLOWERS.}

DANISH DRY WEATHER.-It's main feature is the fact that it will stand an unusual amount of dry or warm weather and still produce perfect, large, solid heads. In districts where heretofore it has been impossible to grow Cauliflower, this fine variety has proven a success. It is ready for market or table about a week later than Extra Early Erfurt. Packet 25c; 1/4 oz. $\$ 1.25$; oz., $\$ 5.00$.

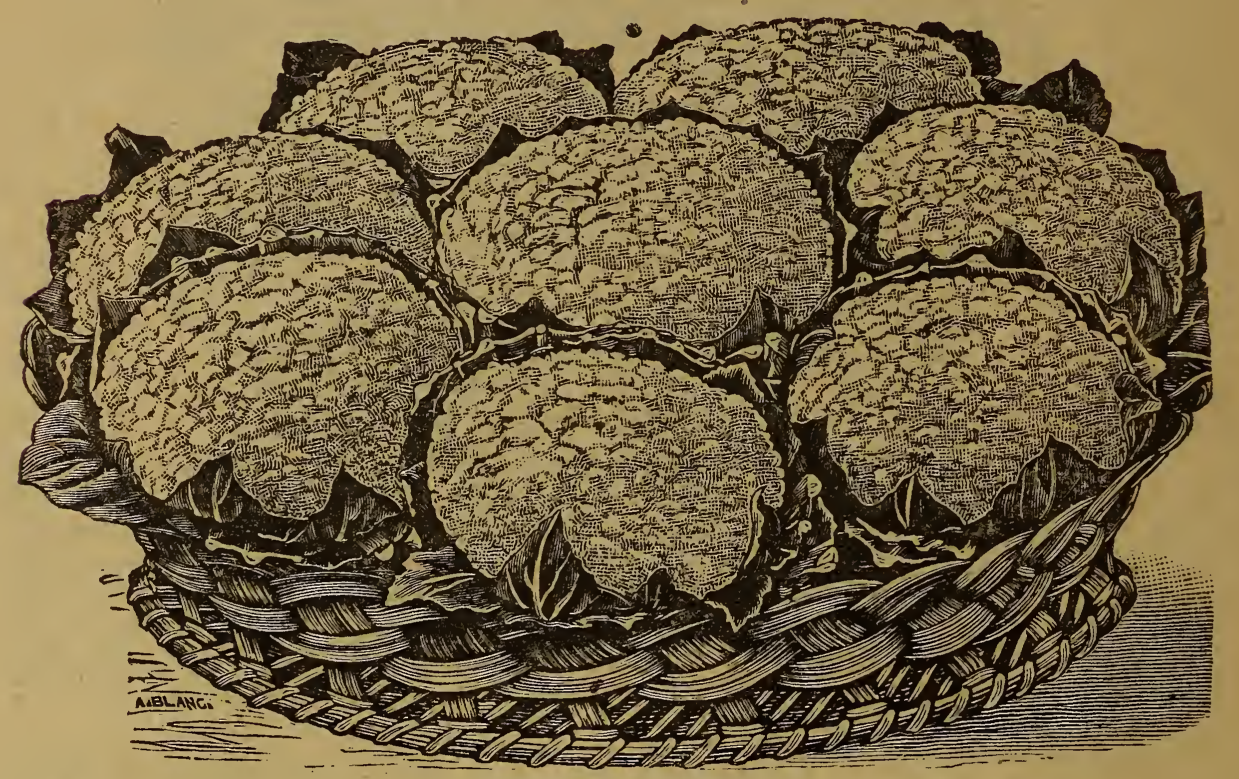

DANISH SNOWBALL.-After testing this strain of Cauliflower in different sections of the country for the past two seasons, I unhesitatingly pronounce it the most satisfactory ever introduced here. It produces large perfect heads of the finest quality. I have imported a supply of seeds from the growers in Denmark. Per oz., $\$ 5.00 ; 1 / 2$ oz., $\$ 2.50$; pkg., $25 \mathrm{c}$.

EXTRA EARLY ERFURT.-Extra selected.-One of the earliest varieties; small leaved dwarf producing very solid pure white heads of the finest quality; about 15 inches high. Do not counfound this variety with the cheaper Early Dwarf Erfurt. Per oz. $\$ 2.50 ; 1 / 2$ oz. $\$ 1.25$; pkg. $25 \mathrm{c}$.

PARIS.-A good variety for succession, head medium, color white, good flavor. Per oz., $\$ 2.50$; pkg., 25c.

EARLY SNOWBALL.-The strain I have of this variety I believe is the very best to be had, grown from the finest specimens; noted for their earliness; large size dwarf habit, uniform shape and compact growth; imported direct from Europe. Per oz., $\$ 7.50 ; 1 / 2$ oz., $\$ 3.50$; pkg., $25 \mathrm{c}$. 
LENORMANDS.-This is the only late variety with which I have been successful and with this I have never had a failure. Heads are large, white and of fine flavor. Per oz., \$2.00; pkg., 25c.

\section{CARROTS.}

These should to grown by every farmer, being useful in feeding all kinds of stock, especially horses, being somewhat laxative, assisting digestion, promoting healthfulness, and adding much to the appearance of the animals. Considering the apparent ease with which they can be grown, too much value cannot be placed upon this crop. It does not require over-rich ground and will produce a crop with less moisture than any other vegetable. The land should be deeply plowed, finely and thoroughly harrowed, smoothed with the back of the harrow, and if not free from lumps, raked by hand. The seed should be sown immediately after the ground is prepared, so that it may come in contact with the natural moisture and the more readily germinate. For garden culture may be sown 15 to 18 inches apart, but where land is plenty they can be double that distance and worked with a cultivator. The sowing may be done as soon as the ground can be worked in spring. to the first of June; from 2 to 4 pounds

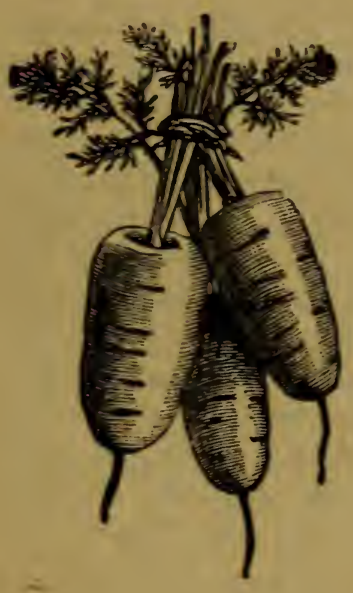
required for an acre, according to distance planted.

EARLY FRENCH FORCING.-This is the earliest carrot in cultivation, and is used exclusively as a table variety. The tops are small, round as a turnip, with small tap root; small size; color very rich orange. Per to., $\$ 1.25 ; 1 / 4$ tb., $40 \mathrm{c}$; oz., $15 \mathrm{c}$; pkg., $71 / 2 \mathrm{c}$.

EARLY SCARLET HORN.-Grown both for table and stock. It has a small top; is deep orange color and of agreeable flavor; can be left in the ground all winter and be pulled as wanted. Per lb. $\$ 1.25 ; 1 / 4$ tb., $40 \mathrm{c}$; oz., $15 \mathrm{c}$; pkg., $71 / 2 \mathrm{c}$.

OXHART, OR GUERAND.-A very desirable variety. Intermediate in length and from 3 to 5 inches in diameter; in quality it is excellent; it is easily gathered, as every one can be pulled by the tops. Per Ib., $\$ 1.25 ; 1 / 4$ tb., $40 \mathrm{c} ; 0 \mathrm{z} ., 15 \mathrm{c} ; \mathrm{pkg} ., 71 / 2 \mathrm{c}$.

DANVERS. - A valuable sort. In form midway between Long Orange and Early Horn. In color it is of a rich shade of orange, growing smooth and handsome. This variety will yield the greatest amount per acre of any sort grown under cultivation; it will easily yield 40 tons per acre. Per lb. $\$ 1.25 ; 1 / 4$ th., $40 \mathrm{c}$; 0z., 15c; pkg., $71 / 2 \mathrm{c}$.

LARGE WHITE BELGIAN.-A very productive sort; grown exclusively for stock; grows about one-third above ground; lower part of root is white, that above ground green. Per to., $\$ 1.00 ; 1 / 4$ to., 30c; 0z., 15c; pkg., $71 / 2 \mathrm{c}$. 


\section{CELERY.}

Celery will do well on almost any soil, provided it is rich and thoroughly worked: The seeds may be sown in a hot bed if the plants are desired early, but for the main crop should be sown in the open ground as early in the spring as the ground can be worked. The seed should be sown thickly in shallow drills and the ground kept damp. One ounce of seed will produce 5000 plants. As soon as the plants appear, carefully hoe them and remove all the weeds; do not allow the weeds to get the least start. Should the vlants be large enough to set out before you are ready for them, the tops should be carefully pulled from the bed, held evenly in the hand until full, when the points of the roots and the tops of the leaves should be cut off, thus facilitating the planting and preventing the tops from wilting; set the plants in double rows about six inches apart. As the plants advance in growth gradually earth up, being careful not to let the earth cover the heart. The averages are numerous, but those catalogued below are among the most

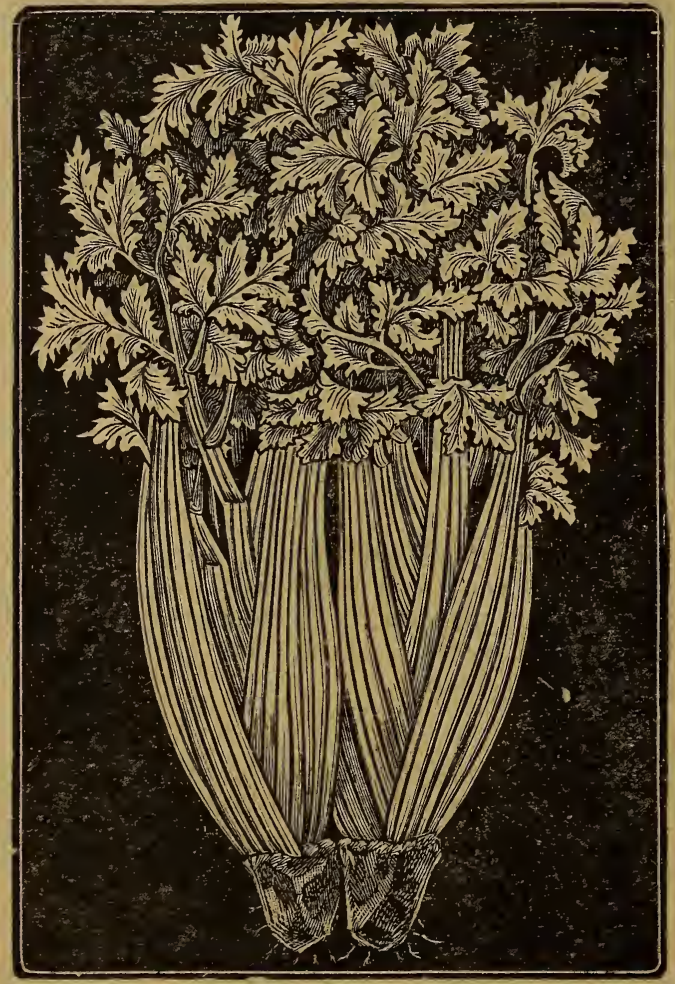
popular.

WHITE PLUME.-This celery is valued because the stalk, the heart and portions of its inner leaves are white; the whiteness does not show, however, until the plants are about one-third grown. By simply tying up the stalks and drawing the soil up with the hoe, the work of bleaching is complete. It is early, ornamental, tender, crisp and good flavor, but not a good keeper. Per tb., $\$ 5.00 ; 1 / 4$ tb., $\$ 1.10$; oz., 20c; pkg., $71 / 2 \mathrm{c}$.

NEW GIANT PASCAL.This is developed from Solid beautiful color, the thick, solid, Golden Yellow. It retains the crisp stalks, and the incompar. able flavor of that variety, but is of much stronger growth, also is longer, producing perfectly bleached stalks over two feet in length and proportionately thick, yet never in the least stringy. A perfect keeper and an excellent shipper, retaining color and a fresh appearance longer than any other sort. Per tb., $\$ 2.25 ; 1 / 4$ tb., $85 \mathrm{c}$; oz., $25 \mathrm{c}$; pkg., $71 / 2 \mathrm{c}$. 
PERFECTION HARTWELL.-A rery large, solid growing variety of excellent flavor, and a creamy white color. In size it is between Golden Dwarf and Large White Solid. It makes an excellent market sort for winter use, as the stalks are clear and attractive in color, with large golden jellow heart and a size to influence purchasers. Very popular. Per 10. ., $\$ 2.25 ;{ }_{4}$ to., $85 \mathrm{c}$; 0z., $25 \mathrm{c}$; pkg.. $71_{2} \mathrm{c}$.

CRAWFORD'S HALF DWARF.-This rariety is a great ravorite. When bleached is of a jellowish-white, making it rery ornamental, entirely solid, jossessing a nutty flavor peculiar to the dwarf kinds, while it has much more vigorous growth, surpassing most of the large growing sorts in weight. Per th., \$2.25; 1/4 Tb.. $85 \mathrm{c}$; 0z.. $25 \mathrm{c}$; pkg.. $71 / 2 \mathrm{c}$.

GOLDEN DWARF.-A showy sort of excellent qualities, solid, of fine flavor and a good keeper, and as its name indicates, possesses when bleached a yellowish golden tint. Per to., $\$ 2.50 ; 1^{1 / 4}$ to., $\$ 5 \mathrm{c} ;$ oz.. $25 \mathrm{c} ; \mathrm{pkg} ., \mathrm{T}^{1}{ }_{2} \mathrm{c}$.

\section{CRESS.}

WATER CRESS.-Sow along a stream of water and keep the weeds from interfering too much until it gets a good start, when it will take care of itself. Valuable as a salad during winter and early spring. Per oz., 60c; pkg., $10 \mathrm{c}$.

CURLED CRESS OR PEPPER GRASS.-Sow thickly in shallow drills. It should be cut often, and will continue to grow. Use as a salad. Per lb. $\$ 1.00 ; 1 / 4$ to., $25 \mathrm{c} ; \mathrm{pkg}$. $71 / 2 \mathrm{c}$.

BROAD LEAVED.-Cultivate same as above. Per $1 \mathrm{~b} .75 \mathrm{c} ; 1 / 4 \mathrm{~b} .25 \mathrm{c}$; pkg. $7{ }_{2}^{1} \mathrm{C}$.

\section{CHICKORY.}

LARGE ROOTED.-Much used as a substitute for coffee. In the fall the roots should be taken up, washed, cut into dices and dried, and when wanted for use should be roasted and ground like coffee. Per $10 ., \$ 1.50 ; 1 / 4$ to., $40 \mathrm{c}$; oz.. $15 \mathrm{c}$; pkg., $\mathrm{i}^{1 / 2} \mathrm{c}$.

\section{CORN SALAD, OR FETTICUS.}

A vegetable used as a salad. It is sown on the first opening of spring in rows one foot apart, and is fit for use in six or eight weeks from sowing. If wanted in early spring, sow in September, cover with straw or hay as soon as cold weather sets in. Can be grown in cold frames, corered with straw mats or shutters, and used any time during the winter. Large leared. Per to.. $\$ 1.50 ; 1+$ to.. $40 \mathrm{c}$; 0z., $15 \mathrm{c}$; pkg., $71 / 2 \mathrm{c}$. 


\section{If to go by mail, add postage.}

The amount of seeds in the hill or row must be in accordance with the season, and when planted early-as it should be for the first crop, even at the risk of having to replant-it must be put in quick thick, as in all probability some will rot, and require about one peck per acre. The time for planting depends upon the locality; here about the 10th of April for earliest. Varieties are named in the order as to earliness.

GOLDEN BANTAM.-Very early, HARDY, small but compact ears, and the richest, sweetest corn you ever ate. Per Ib., 30c.

PEEP O'DAY.-From ten days to two weeks earlier than any other sort and one of the sweetest of all extra varieties. Per $1 \mathrm{~b} ., 30 \mathrm{c}$.

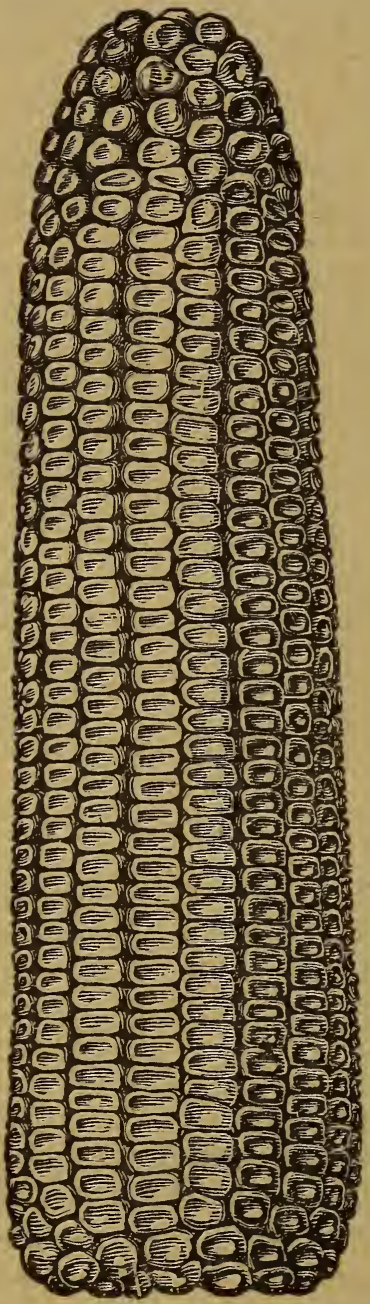

WHITE CORY.-One of the earliest varieties of sweet corn known. Has a large ear, considering size of stalk, small cob, well filled with broad grains. It is larger eared and at least one week earlier than the Marblehead. Per 1b., 30c.

MOORE'S EARLY CONCORD.-About the same season as above, of strong growth, producing large well filled ears of good quality. Per 1b., 30c.

EARLY MINNESOTA.-One of the best second early sorts; white grains and cob; ears of good size, being desirable market sort. Per Ib., 30c.

EARLY EVERGREEN.-This is a first-class variety coming in about two weeks in advance of late Evergreen and of the same excellent quality. It is very productive, producing large well filled ears, with broad kernels and very small cob, filled well over the tips. There is no sweeter or handsomer corn grown, and commands a ready sale in market. Per 1b., 30c.

BLACK MEXICAN.-The sweetest and most desirable for family use. When dry the kernels are black. The corn is not equaled in tenderness and sweetness by any other sort. Per Ib., 30c.

COUNTRY GENTLEMAN.-As a table corn this variety stands unrivaled, and, without doubt, is the most luscious of all sweet corns. The plump pearly white kernels are of great depth, most delicious, and the flavor will delight an epicure. The ears are just the size to be attractive on the table, have very small cob, and owing to the heavy husk protection, retain their delicious tenderness beyond the usual period. Per 1b., 30c.

STOWELL'S EVERGREEN.-Grown more extensively than any other late variety. It is a great favorite with market gardeners for late use. The ears are of large size, kernels are broad, deep, tender and sugary; very productive and remain a long time in fit condition for table use. Per tb., 30c.

\section{FIELD CORN.}

WASHINGTON EARLY GOLDEN DENT and WASHINGTON WHITE DENT.-Per 1b. 10c; per 100 Ibs. $\$ 8.00$. 


\section{CUCUMBERS}

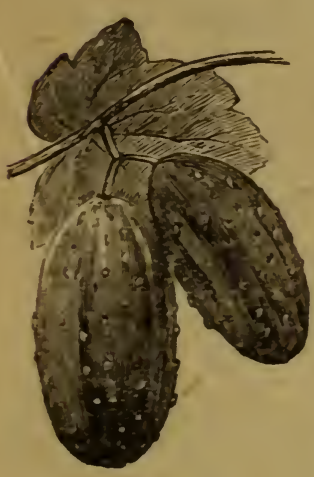

The soil best adapted to cucumbers is a sandy loam. and they will do well on a very sandy or gravelly land if an abundance of manure is applied. In planting for early crop double the quantity of seed should be used, certainly a dozen to the hill, as a great many will rot. Cover one inch deep and $\mathrm{L}$ ress the soil down over the hill with the hoe. When nicely up thin to three in a hill. They should be planted about $4 \frac{1}{2}$ feet apart each way, requiring about $1 \frac{1}{2}$ pounds of seed per acre. For pickles, the time for planting is about the middle of June to the first of July.

EARLY FRAME.-An old favorite variety for either pickling or used as a slicing; handsome in appearance; earliest good cucumber grown and therefore a great favorite for marketing. Per tb., $\$ 1.25 ; 1 / 4$ tb., $40 \mathrm{c}$; oz., $15 \mathrm{c}$; pkg., $71 / 2 \mathrm{c}$.

EVERGREEN WHITE SPINES.-This is an improvement of the old white spined variety, extra long and of the finest quality, very straight and uniformly even in shape; color a beautiful green and in all respects a remarkably handsome variety, and an excellent shipper. Per to., $\$ 1.25 ; 1 / 4$ tb., $40 \mathrm{c}$; oz., 15c; pkg., 71/2c.

EARLY RUSSIAN.-Very early; valuable only in private gardens, being too small for shipping purposes. Per tb., \$1.25; $1 / 4$ th., $35 \mathrm{c}$; oz., $15 \mathrm{c} ; \mathrm{pkg}$., $71 / 2 \mathrm{c}$.

IMPROVED EVERGREEN.-This is a wonderfully prolific sort, quite early, crisp and tender, of excellent flavor; the cucumbers retain their beautiful green color longer than ordinary sorts. Per th., $\$ 1.25 ; 1 / 4$ to., $40 \mathrm{c}$; oz., $10 \mathrm{c}$; pkg., $71 / 2 \mathrm{c}$.

CHICAGO, OR WESTERFIELD'S PICKLING.-This is one of the finest varieties that can be grown for pickling purposes, and in some districts it is grown for that purpose to the exclusion of all others. Per tb., $\$ 1.25 ; 1 / 4$ ith., $1 / 4$ tb., 40c; oz., $40 \mathrm{c}$; pkg., $71 / 2 \mathrm{c}$.

JERSEY PICKLE.-This is the variety used exclusively in New Jersey by those who prepare pickles commercially. It is very productive, and is said to "green" better than any other sort, and to hold color. Per tb., $\$ 1.25$; $40 \mathrm{c}$; oz., 15c; pkg., $71 \frac{1}{2} \mathrm{c}$.

LONG GREEN TURKEY.-This is extensively grown, and is an old, well known standard variety. It is of superior quality; grows to a length of from nine to twelve inches; vines are vigorous and productive; used largely for pickling. Per tb., $\$ 1.50 ; 1 / 4$ tb., $40 \mathrm{c}$; oz., $15 \mathrm{c}$; pkg., $7 \frac{11 / 2}{\mathrm{c}}$.

JAPANESE CLIMBING.-Vines are extra long and vigorous. Is very prolific, producing in profusion; fruit about ten inches long, thick and of finest flavor. Per th., $\$ 1.50 ; 1 / 4$ tb., $40 \mathrm{c}$; oz., $15 \mathrm{c}$; pkg., $71 / 2 \mathrm{c}$.

SERPENT OR SNAKE.-Grows very of ten to a length of six feet, retaining even then its quality, which is fair. Almost an interesting curiosity, much resembling a snake curled up with head pratruding. Per pkg. 10c.

LONG GERMAN.-An imported variety from Germany, attaining a length of from 18 to 22 inches. Fine shape, grow ing very straight and smooth. Most desirable for exhibition purnoses. I'er okg. 10c; oz. 30c. 


\section{ENDIVE.}

Sow in June, July and August. Cover lightly, when up thin out to eight inches apart and give clean culture. When the leaves are about eight inches long blanch by gathering in the hand and tying near the top with some soft material. At the approach of winter take up carefully with a ball of earth to each plant and place in frame or cellar for use. Keep dry and let them have plenty of air or they will rot.

GREEN CURLED.-The standard variety. Per oz., 20c; pkg., $71 / 2 \mathrm{c}$.

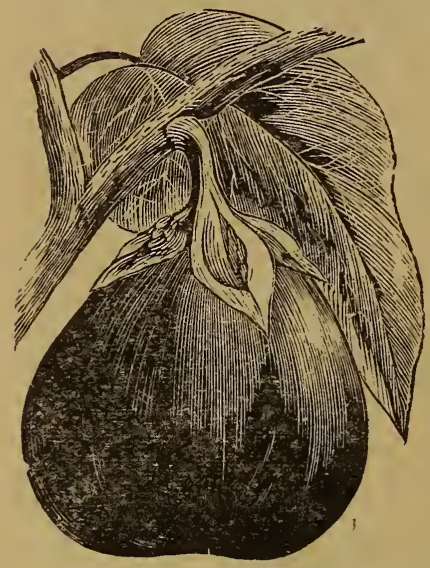

EGG PLANT.

Should be sown in hot bed early in spring and transplanted when two inches high to a second hot bed. If that is not done, thin to four inches apart. Do not plant out until the weather becomes warm. Cool nights or cold storms will check their growth. Set plants $2 \times 3$ feet apart.

IMPROVED NEW YORK PURPLE.-The best; large, oval, deep purple. Grown more extensively than other. Per oz., 65c; pkg. $10 \mathrm{c}$.

\section{KOHL RABBI.}

Sow in spring in rows 18 inches apart, afterwards thinning the plants to 10 inches. Keep the weeds down, and when the thickened stem is three inches through they are fit to eat, and should be used at once, being tough when old. They are cooked the same at turnips.

EARLY WHITE VIENNA.-This is the most popular sort, being handsome and delicate. Per oz., 25c; pkg., $7 \frac{1}{2} \mathrm{c}$.

\section{LEEK.}

Sow in the early spring same as onions, and about first of July transplant into rows about 18 inches apart, and six inches in the row. Draw the earth up to them as they grow. They require rich soil and clean cultivation.

LARGE LONDON.-The standard sort. Per tb., $\$ 3.50 ; 1 / 4 \mathrm{lb} ., 90 \mathrm{c} ; \mathrm{oz}$. $30 \mathrm{c}$; pkg., $71 / 2 \mathrm{c}$.

\section{LETTUCE.}

For early spring use should be sown about September 1 in highly manured soil, in rows about 15 inches apart and one-half inch deep. For this purpose "Philadelphia Butter" is the variety usually sown, it being considered the most hardy variety. Usually lettuce will stand out, with us, during winter, without protection. For summer use sow as early as the ground can be worked.

BLACK SEED SIMPSON.-A very popular sort among market gardeners everywhere. Forms a large loose head; is nearly white, curly leaves, are large, thin, exceedingly tender and of excellent quality. Per $\mathrm{tb} ., \$ 1.25 ; 1 / 4 \mathrm{HD}$., $40 \mathrm{c}$; oz., 15c; pkg., $7 \frac{1 / 2}{2} \mathrm{c}$. 


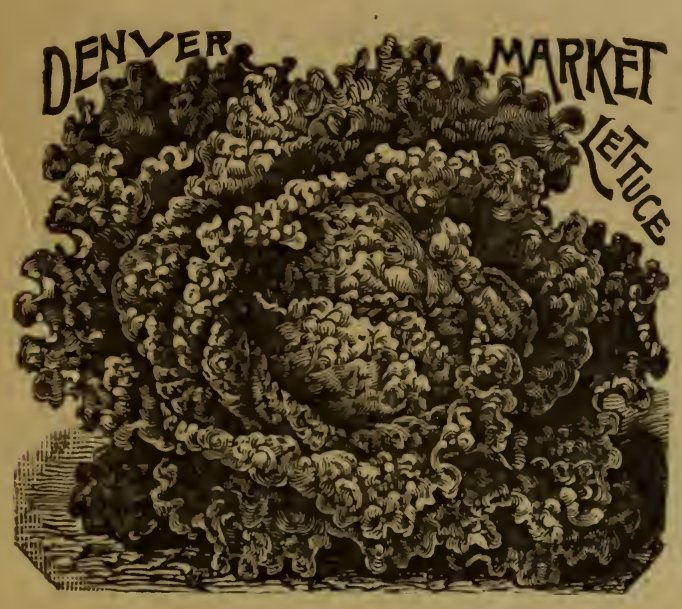

DENVER MARKET.-This is an early variety of head lettuce-it forms a solid head of light green color and is slow to shoot to seed; the leaves are somewhat blistered like Savory cabbage. It is crisp and tender at all stages of growth. Per lb. $\$ 1.25 ; 1 / 4$ tb., $40 \mathrm{c}$; oz., $15 \mathrm{c}$; pkg., $71 / 2 \mathrm{c}$.

\section{FERRY'S PRIZE HEAD.-}

For home use or near a market this sort is very desirable, being tender, brittle and sweet. It wilts quickly, however, and will not bear shipment. Per to., $\$ 1.25$; $1 / 4$ lb., 40c; oz., 15c; pkg., 71/2 c.

EARLY CURED SIMPSON.-Similar to the preceding. It does not form a solid head, but will produce a mass of loose, tender leaves of finest flavor, growing a foot or more in aiameter. Per Ib., $\$ 1.25 ; 1 / 41 \mathrm{~b} ., 40 \mathrm{c}$; oz $15 \mathrm{c}$; pkg., $71 / 2 \mathrm{c}$.

HANSON.-Produces a large head of excellent flavor, crisp and tender; it is not a good shipping variety, however. Per $1 \mathrm{~b} ., \$ 1.25 ; 1 / 4 \mathrm{tb} ., 40 \mathrm{c}$; oz., $15 \mathrm{c}$; pkg., $71 / 2 \mathrm{c}$.

GRAND RAPIDS.-Forcing, seed black. As a lettuce for green house forcing this variety undoubtedly stands at the head of the list. The plant is upright and forms a loose head or cluster of large, light green leaves, slightly crimped and blistered and rather thin. It, will stand shipping long distances better than most sorts. Per tb., $\$ 1.50 ; 1 / 4$ tb., $45 \mathrm{c} ;$ oz., $15 \mathrm{c} ;$ pkg., $71 / 2 \mathrm{c}$.

LOS ANGELES OR NEW YORK.-A large, crisp, great favorite in the markets of Los Angeles and San Francisco. This is a lettuce much raised around New York whence its name was taken. The quality is the finest and is an excellent lettuce for the garden. Pkt., $7 \frac{1}{2} \mathrm{c}$; oz., $15 \mathrm{c} ; 1 / 4 \mathrm{tb}$., $45 \mathrm{c} ; \mathrm{Ib} ., \$ 1.50$.

PHILADELPHIA BUTTER, OR EARLY WHITE HEAD.-A thick-leaved, smooth lettuce, round dark green leaves formed into a very solid round head; stands a long time without running to seed. The inner leaves blanch a rich yellow; quality first class. Per tb., $\$ 1.50 ; 1 / 4$ Ib., $40 \mathrm{c} ; 0 \mathrm{z}$., $15 \mathrm{c}$; pkg., $71 / 2 \mathrm{c}$.

ICEBERG.-A beautiful lettuce worthy of universal cultivation. The quality is simply perfect. Large curly leaves of light green with a very light reddish tinge at the edges. The usual solidity of the heads is insured by the Jarge white main ribs of the leaves, each of which curves to the center, which is thoroughly blanched. Per tb., $\$ 1.25 ; 1 / 4$ tb., $40 \mathrm{c} ;$ oz., $15 \mathrm{c}$; pkg., $71 / 2 \mathrm{c}$.

\section{MUSK MELONS.}

Select a rich, sandy soil and after danger of frost is over and the ground has become one of the most profitable shippers. Per 1t., $\$ 1.15 ; 1 / 4$ tb., $35 \mathrm{c}$; plenty of seed to insure a good stand. When up and out of danger pull out all but three plants. Cultivate until the vines cover the ground and it is a good plan to pinch the ends of the growing shoots to induce early fruiting. 
As it is desirable to have melons as early as possible, a portion of the crop may with advantage, be started in a hot bead, by using pots, sods or Hallock berry baskets filled with rich earth. They should not be removed from the bed until settled warm weather. It is quite important that proper soil be selected for growing musk melons, as on heavy soil the quality is usually poor.

ROCKY FORD.-This has become one of the most popular of early melons. The fruit is oval, slightly ribbed, densely covered with coarse netting. Flesh thick, green and very sweet;-uniform in shape and quality, and has become one of the most profitable shippers. Per 1b. $\$ 1.00 ; 1 / 4$ 1b. 30c; oz., 15c; pkg., 71/2 c.

EXTRA EARLY, CITRON.-These are the first to be seen in the market, and for this reason valuable to market garderers. It is medium in size, green fleshed, of good flavor, extremely early and very productive. No wide-awake gardener can afford to be without this variety. Per to., $\$ 1.25$; $1 / 4$ tb., 35c; oz., 15c; pkg., $71 / 2 \mathrm{c}$.

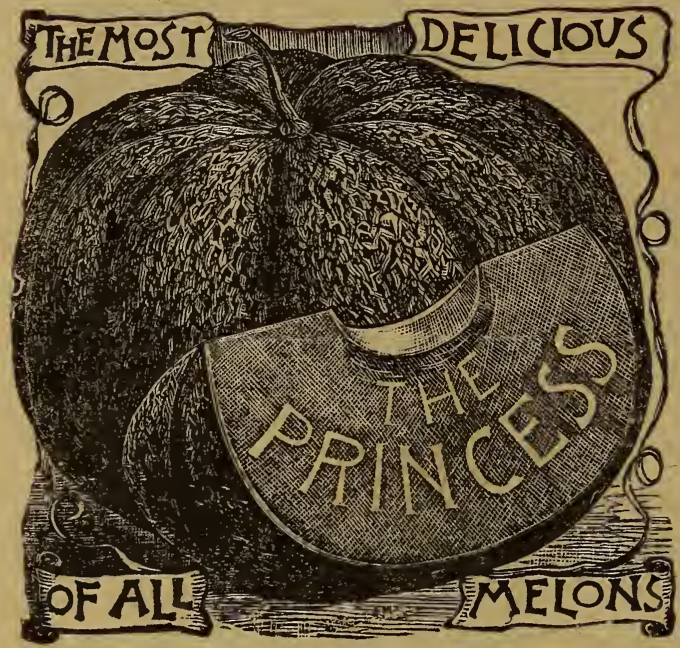

THE PRINCESS-This has for several years been the leading Musk Melon in this market, and it is a general favorite wherever introduced. The flesh is a deep, rich salmon color, very thick and of splendid flavor. Per tb., $\$ 1.25 ; 1 / 4$ tb., $35 \mathrm{c}$; oz., 15c; pkg., $71 / 2 \mathrm{c}$.

MONTREAL. - A Showy melon, average weight 10 to 15 pounds, well ribbed and netted. Flesh deep, sugary, green in color, fine flavor and very attractive. Per $\mathrm{Ib} ., \$ 1.25$; $1 / 4$ tb., 35c; oz., 15c; pkg., $71 / 2$ c.

MONROW.-This is, without a doubt, one of the finest meluns in cultivation; a deep bronze yellow on outside, salmon color inside, grows to large size. Per tb., $\$ 1.25$; $1 / 4$ tb., 35c; oz., 15c; pkg., $7 \frac{1}{2}$ c.

EARLY HACKENSACK.-This is one of the leading green fleshed sorts. It produces melons equally as large and with all the good qualities of Old Hackensack, but two weeks earlier. Heavy netted and of delicious flavor. Its shape and solidity admits of its being packed very closely in crates for shipment, and it will keep in good condition several days after being packed. Per th., $\$ 1.25$; $1 / 4$ tb., 35c; oz., 15c; jkg., $71 / 2 \mathrm{c}$.

MILLER'S CREAM.-Or Osage.-This is another salmon-colored melon, very sweet and melting in quality, and so thick that the melon is almost solid, with very thin rind. The vine is a strong grower and very productive. Per to., $\$ 1.25$; $1 / 4$ to., $35 \mathrm{c}$; oz., 15c; pkg., $7 \frac{1}{2} \mathrm{c}$. 
GARDEN LEMON.-Per pkg. 5c.

LIVINGSTON'S TIP TOP.-The seed I offer is from the originators. This melon stands at the head in handsome appearance, productiveness and general excellence. Flesh deep salmon color, rich, sweet and juicy. Per to. $\$ 1.50 ;{ }_{+}^{1}$ Tb., 40c; oz., $15 \mathrm{c}$; pkg., $i^{1} \% \mathrm{c}$.

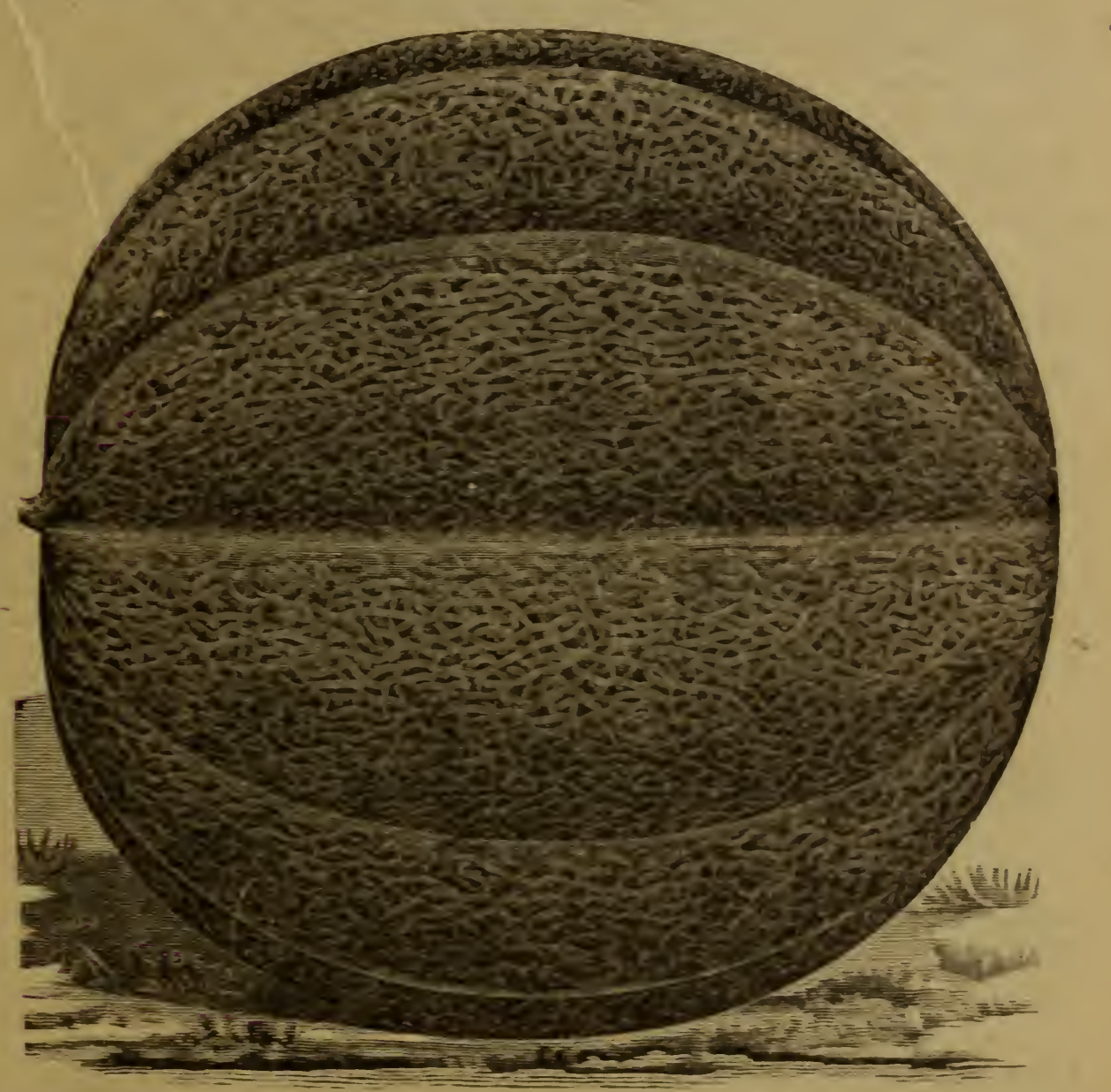

LARGE YELLOW CANTALOUPE.-This comes recommended as an extraordinary melon in several particulars, among which are size, quality, solidity, fineness of grain, shipping and keeping qualities and great productiveness. Flesh is yellow, as name inficates. Per it . \$1.25; 14 it., $35 \mathrm{c}$; oz., $15 \mathrm{c}$; pkg.. $7_{1} \mathrm{c}$. 


\section{WATERMELONS.}

Treat the same as Musk Melon, except that they should be planted $8 \times 8$ feet. Watermelons should be marketed when ripe, for if allowed to get over ripe, they will become worthless-and yet they must be ripe to be saleable. The question may arise, "When is a watermelon ripe?" Some judge by the curl of the stem, which becomes dry when the melon is ripe; others press the melon with the hand and if ripe the flesh within cracks, which may be known by the sound emitted, but this is injurious, and hence is objectionable. The surest test is by sight, feeling and sound. When ripe the color of the skin is duller than when growing; the rind, or outer flesh, is spongy when growing, but firm when mature; and there is a peculiar sound created within the ripe fruit when merely "snapped" by the middle finger, which cannot be described, but with which the ear becomes familiar with practice. "The proper way is to compare the color, feeling and sound between known unripe and supposed ripe fruit, and determining by cutting the latter. A very few trials will give you the requisite knowledge, which, when once acquired, can never be forgotten.

FORDHOOK EARLY.-This is an extra meion of large size. The form much resembles Dark Icing. The rind is tough and the outer color is medium green; seeds are white; the flesh is very sweet and melting; an excellent shipper. Per 1b., $\$ 1.00$; $1 / 4$ Ib., $30 \mathrm{c}$; oz., $15 \mathrm{c}$; pkg., $71 / 2 \mathrm{c}$.

PHINNEY'S EARLY.-A very early variety of medium and uniform size and beautiful form. The skin is tough and smooth, with uniform narrow stripes. Flesh bright red, sweet and delicious, and a good shipping vaiety. Per th., $\$ 1.00 ; 1 / 4$ th., 30c; oz., 15c; pkg., $7 \frac{1}{2} \mathrm{c}$.

DARK ICING.-This is an excellent sort of medium size, and early maturity. The skin is dark green and firm. The flesh is a deep, rich scarlet, of delicious flavor; it is one of the best shipping and carrying melons grown. Per tb., $\$ 1.00$; $1 / 4$ tb., 30c; oz., 15c; pkg., 71/2 c.

SWEETHEART.-This grand new melon is one of the earliest; large, handsome, good keeper; fruit large, rind thick but firm, ripens early, flesh very bright red, solid and thick. All melon growers should plant it. Per tb., $\$ 1.00 ; 1 / 4$ lb., 30c; oz., $15 \mathrm{c}$; pkg., $71 / 2 \mathrm{c}$.

ICE CREAM.-True seed. This is a general favorite and largely grown. It is of medium size, early; skin is light in color, thin rind, flesh solid, scarlet, crisp and excellent flavor. Per tb., $\$ 1.00 ; 1 / 4$ tb., $30 \mathrm{c}$; oz., $15 \mathrm{c} ; \mathrm{pkg} ., 71 / 2 \mathrm{c}$.

DIXIE.-A comparatively new melon with many good qualities. In shape it is oblong, attaining a good size; skin thin, tough and beautifully marked; flesh deep scarlet, crisp, sugary, firm and solid. . Never mealy or tough. It is a wonderful shipper, keeping a long time after being gathered, and still retaining its excellent qualities. Per tb., $\$ 1.00 ; 1 / 4$ tb., $35 \mathrm{c} ; 0 z ., 15 \mathrm{c}$; pkg., $71 / 2 \mathrm{c}$. 


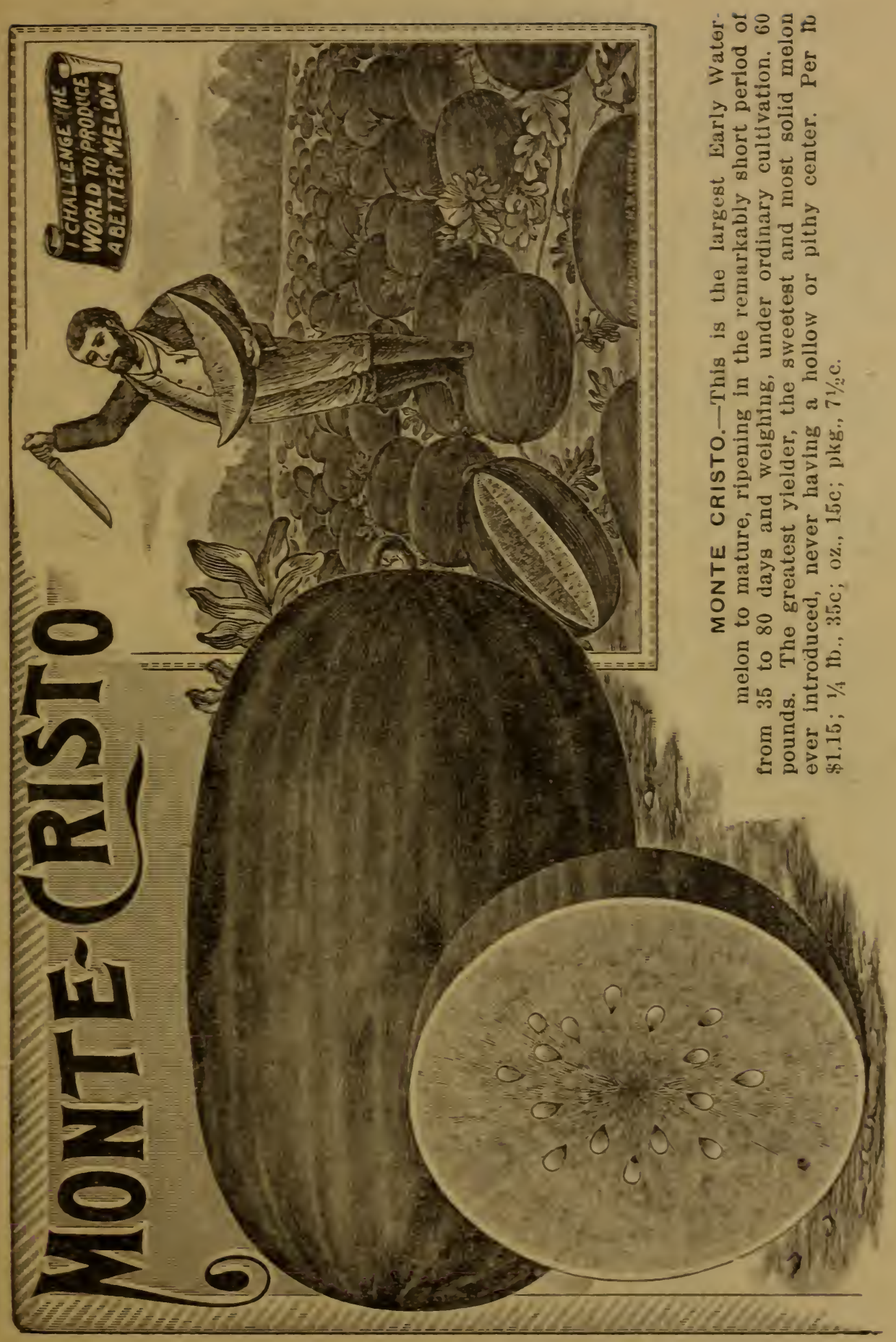


KOLB'S GEM.-The skin is dark green, marbled with lighter shades; shape slightly oval; size large and remarkably uniform, rind very thin and tough, flesh tender, melting, of excellent quality. Per $1 \mathrm{~b} ., \$ 1.00 ; 1 / 4 \mathrm{lb} ., 30 \mathrm{c}$; oz., $15 \mathrm{c}$; pkg., $7 \frac{1}{2} \mathrm{c}$.

LONG LIGHT ICING.-This we consider the finest melon grown for family use or a near market. In shape it resembles the Ice Cream, and is of almost equal earliness. They are universally good, with very thin rind; crisp, juicy flesh, and a richness of flavor equalled by few melons. Per lb. $\$ 1.00 ; 1 / 4$ tb., $30 \mathrm{c}$; oz., $15 \mathrm{c}$; pkg., $7 \frac{1}{2} \mathrm{c}$.

HALBERT'S HONEY.-Of splendid quality and especially for home use or nearby markets; has a dark green skin, very thin rind, meat red, sweet and tender. Per tb., $\$ 1.00 ; 1 / 4$ tb., 30c; oz., 15c; pkg., $71 / 2 \mathrm{c}$.

CUBAN QUEEN.-Fruit medium to large, globular or oval; skin striped light and dark green; rind medium thick, stands shipping well. Flesh bright red; solid, very crisp, tender and sugary. Per 1b., $\$ 1.00 ; 1 / 4 \mathrm{tb} ., 30 \mathrm{c} ; 0 \mathrm{z} .15 \mathrm{c}$; pkg., $7 \frac{1}{2}$ c.

FLORIDA FAVORITE.-A fine variety, of medium size, oblong in shape, color of rind dark and light green stripes alternately; flesh bright crimson, very crisp and deliciously sweet. Can be classed with the second early sorts. Per 1b., $\$ 1.00 ; 1 / 4$ Ib., 40 c; oz., 15c; pkg., 71/2 c.

SOUTHERN RATTLESNAKE, OR GYPSY.-Fruit oblong, skin light green, beautifully striped; thin rind; flesh scarlet, solid and deliciously sweet. Pkg., $71 / 2$ c; oz., $15 \mathrm{c} ; 1 / 4$ tb., $30 \mathrm{c}$; to., $\$ 1.00$.

TOM WATSON.-A large, oblong melon, quite distinct from other varieties. The flesh is deep red, crisp, melting and of the finest flavor. It is a most excellent shipper and very handsome in appearance. Per $1 \mathrm{~b} ., \$ 1.15 ; 1 / 4$ ib., $30 \mathrm{c}$; oz., $15 \mathrm{c}$; pkg., $71 / 2 \mathrm{c}$.

PRESERVING CITRON.-A round dark and light striped Watermelon; meat greenish white. Used for preserving only. Per oz., 15c; pkg., $7 \frac{1}{2} \mathrm{c}$.

\section{MUSTARD.}

Sow thickly during early spring in shallow drills and press the earth down well. For fall salad sow in September.

BLACK MUSTARD.-These seeds form the mustard of commerce. Per Ib., $75 \mathrm{c} ; 1 / 4$ tb., $25 \mathrm{c}$; pkg., $7 \frac{1}{2} \mathrm{c}$.

WHITE LONDON.-Leaves used for salad while young; grows very rapidly. Per 1 b., $75 \mathrm{c}$; $1 / 4$ tb., $25 \mathrm{r} ;$ pkg., $71 / 2 \mathrm{c}$. 


\section{NASTURTIUM.}

Sow as soon as all danger of frost is past, in drills about an inch deep. The tall kinds require fences or poles on which to climb. The seeds are used in flaroring pickles or as a substitute for capers.

$$
\begin{aligned}
& \text { TALL MIXED.-Per to., } \$ 1.50 ; 1 / 4 \text { tb., 50c; oz., 15c; pkg., } 7^{1}{ }_{2} \mathrm{c} \text {. } \\
& \text { DWARF MIXED.-Per to.. \$1.50; } 1 \frac{1}{4} \text { tb.. 50c; 0z.. } 15 \mathrm{c} ; \text { pkg., } i \frac{1}{2} \mathrm{c} \text {. }
\end{aligned}
$$

\section{ORKA, OR GUMSO.}

The cultivation of this regetable is similar to sweet corn, the requirements being the same. The seed should not be planted until settled warm weather and even then a portion of the seed will rot in the ground. It is well to use plenty of seed, planting about $2 \times 3$ feet and when nicely up thin to three or four in a hill.

DWARF ORKA.-This is the variety usually grown, as it is more productive than the tall sorts, and the quality is the same. Per lb. $60 \mathrm{c} ; 1 / 4 \mathrm{lb} .20 \mathrm{c}$; oz., 10c; pkg., $71 /, 2$ c.

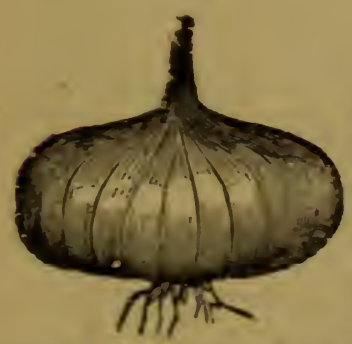

\section{ONIONS.}

For onions the ground should be plowed in the fall, and if manure is to be used, turning under a good coat at that time, throwing the furrows out and leaving the ground without harrowing. In the spring as soon as the ground can be worked, harrow and then plow again. After plowing, throw the harrow, going over the ground with the back down; turn the teeth down and harrow thoroughly; back it off again, which should leave it in good condition for planting. Stretch a line on one side and follow with a drill set to plant one inch deep. The marker should be set to make the rows about 16 inches apart. The wheel, which is attached to most garden drills, will firm the soil sufficiently. As soon as the seed is planted go over with a garden cultivator and continue this every week until the onions are $3-4$ inch in diameter, thus saving all hand weeding, and with a properly adjusted Hill dropper, which will deposit the seed about as desired, there will be little if any, hand work with the crop. In this manner of planting it is of the highest importance to have seed of the highest germ. inating power; otherwise a good stand will not be had and a consequent loss will result. The seed I offer is of a superior quality, grown from perfect well matured onions, and any gardener recognizes the fact that the finer, the better it will produce, and the consequent higher price will be charged for it. I never have, and do not propose to compete in prices with seeds grown from inferior bulbs.

NEW WHITE QUEEN.-Is a fine, early silver-skinned rariety, of beautiful form and rapid growth. Seeds sown in early spring will produce onions two inches in diameter in early summer. Per $10 ., \$ 5.00 ; 1 / 4$ to.. $\$ 1.50 ; 0 z .050 \mathrm{c}$; pkg., $71 / 2 \mathrm{c}$. 
EARLY RED GLOBE.-A very handsome variety, and deserving of general cultivation. It matures very early, grows to a medium size, and is a good keeper. The skin is deep red; flesh fine grained and tender; flavor mild. Per tb., $\$ 3.00$; $1 / 4$ tb., $80 \mathrm{c}$; oz., $25 \mathrm{c}$; pkg., $71 / 2 \mathrm{c}$.

EARLY FLAT RED.-A variety of unusually early maturity for a large red. While not so large as Red Wethersfield, they are at least two weeks earlier, and large enough for any market. Some strains sold as Extra Early Red or two weeks behind this sort. Per tb., $\$ 2.50 ; 1 / 4$ 1b., $75 \mathrm{c} ;$ oz., $30 \mathrm{c}$; pkg., $71 / 2$ c.

AUSTRALIAN BROWN.-This onion resembles Oregon Yellow Danvers in general appearance, but has a clear, amber-brown skin that attracts buyers. It matures early, ripens uniformly and will keep in good condition longer than any other onion. Pkg., 71/2c; $1 / 4$ tb., 70c; tb., $\$ 2.25$.

OREGON DANVERS.-This splendid variety is universally grown for shipping and commands the highest price in any market. It produces a thick, flat bulb, with small neck and rich yellow skin. It is fine grained and heavy, of mild flavor, a good cropper, and an excellent keeper. Per 1b., $\$ 2.25 ; 1 / 4$ tb., $70 \mathrm{c}$; oz., $25 \mathrm{c}$; pkg., $7 \frac{1}{2} \mathrm{c}$.

LARGE RED WETHERSFIELD.-Of large size, fine form, skin purplish red, moderately fine grained, rather strong flavor; very productive and a good keeper. This is the staple variety with Eastern growers. Per tb. $\$ 2.50$; $1 / 4$ lb., 70c; oz., 25c; pkg., 71/2 c.

YELLOW GLOBE DANVERS.-Buxtons strain.-This is the very best type of this old favorite variety, true globe-shaped and symmetrical. Grows to large size, fine grained and very heavy; of mild flavor and a good keeper. Per tb., $\$ 2.75$; $1 / 4$.tb., 80c; oz., 25c; pkg., $71 / 2$ c.

ITALIAN YELLOW GLOBE.-A large yellow globe onion, enormous yielder, early, mild and sweet, but not a long keeper. Per Ib., $\$ 2.50 ; 1 / 4 \mathrm{lb}$., $50 \mathrm{c}$; oz., $20 \mathrm{c}$; pkg., $7 \frac{1}{2} \mathrm{c}$.

SPANISH KING, OR PRIZE TAKER.-American grown seed. A large yellow skinned variety of perfect globe shape. The necks are small and they ripen up well, but the flesh is not so firm as the preceding, but is larger, and milder in flavor. Per lb., $\$ 2.75 ; 1 / 4$ tb., $80 \mathrm{c}$; oz., $25 \mathrm{c}$; pkg., $7 \frac{1}{2} \mathrm{c}$.

WHITE PORTUGAL.-Early, of immense size. Flavor mild and pleasant; skin silver white; of handsome appearance, highly esteemed for pickling when thickly sown. You will make no mistake by planting this excellent variety. It will give perfect satisfaction. Per $1 \mathrm{~b} ., \$ 4.00 ; 1 / 4 \mathrm{lb} ., \$ 1.20 ;$ oz., $40 \mathrm{c}$; pkg., $7 \frac{1}{2} \mathrm{c}$.

ONION SETS.-Bottom sets grown from seed, one quart weight about one pound. Per 1b., $30 \mathrm{c}$.

\section{PARSLEY.}

In planting, the seed will germinate more readily if soaked a few hours in lukewarm water. Sow early in the spring and when well up thin to 6 inches apart.

DOUBLE CURLED.-The plant is of dwarf habit with leaves finely cut and very curly; and is the variety usually grown. Per $1 \mathrm{~b} ., \$ 1.25 ; 1 / 4 \mathrm{lb} ., 35 \mathrm{c}$; oz., 15c; pkg., $71 / 2 \mathrm{c}$. 


\section{PARSNIPS.}

Parsnips require a good, strong soil, deeply plowed or dug. As the seed is very light, naturally weak in the germ, it should be sown thickly in rows

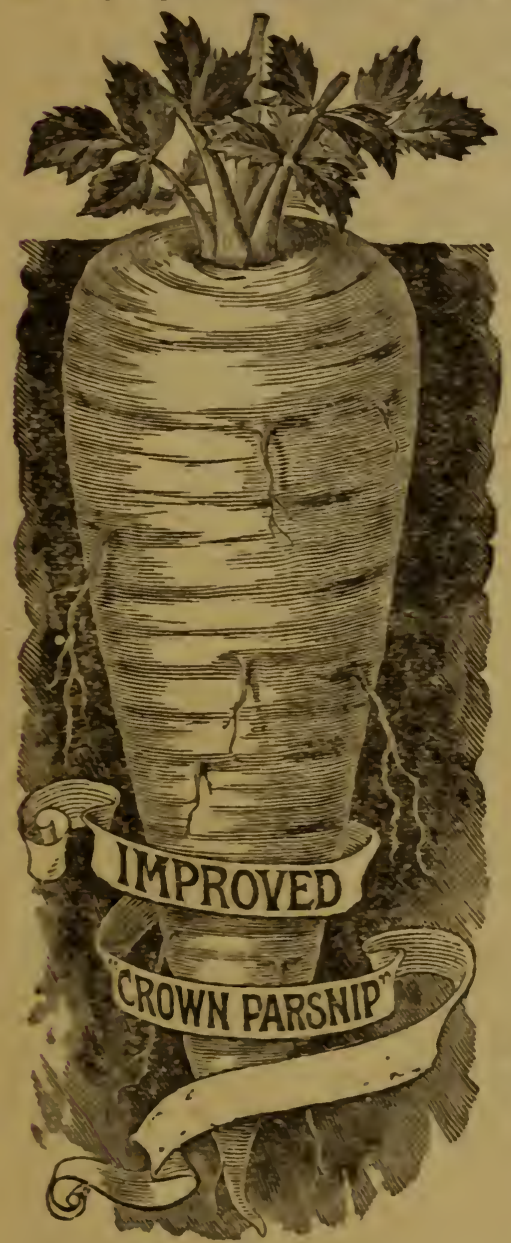

is inches apart and about half an inch deep, and the plants thinned to 4 inches when well up. They may be sown trom early spring to June 1 , but early sowing is advisable, as the seed will not germinate readily in hot, dry weather. Four pounds will plant one acre.

LARGE SUGAR LOAF OR HOLLOW CROWNED.-This is the best variety now grown. The roots are intermediate in length, white, sugary, of finest flavor, and easily harvested. Per th., $\$ 1.50 ; 1 / 4$ to., 35c; oz., 15c; pkg., 71/2c.

\section{PEAS.}

If it go by mail, add parcel postage.

Peas require a moderately rich soil, and for early crop, light, dry soil. Sow the seed as early as the ground can be worked, in rows three feet apart for dwarf and four feet for tall growing sorts. When planted very early the furrows should be about four inches deep and seeds planted one inch apart and covered about twn inches for the smooth varieties and from one-half to one inch for the sweet or wrink.ed sorts, which will rot if planted early and covered deep. Fill up the furrowing during cultivation. One pound will plant about 50 feet of row; about two bushels per acre.

EXTRA EARLY ALASKA.-This tine pea has become a standard extra early market variety, and is the earliest of all blue peas; grows about thirty inches, very uniiorm in maturing the crop, of excellent quality, and retains its desirable color after cooking. Per tb., 25c.

FIRST AND BEST.-Same as above; time of ripening and quality the same. Price the same.

GRADUS.-The finest extra early pea yet introduced. This valuable creation fills a place not hitherto occupied by any kind of peas. The vine of this most distinct sort is like the First and Best, except that it grows a little taller and matures its pods a little later. The immense pods are almost as large as those of the Telephone, uniformly well shaped and handsome. 
They ripen slowly and continue fit for use much longer than most varieties, making this by far the most desirable sort for the home garden. The peas are very large, of splendid quality and beautiful color, which they retain after cooking. Per Ib., 30c.

AMERICAN WONDER.-A hybrid between Little Gem and Champion of England. It is an extra early dwarf variety and has ben for years the standard early wrinkled variety, sweet and excellent in quality and quite productive. Per $1 \mathrm{~b} ., 30 \mathrm{c}$.

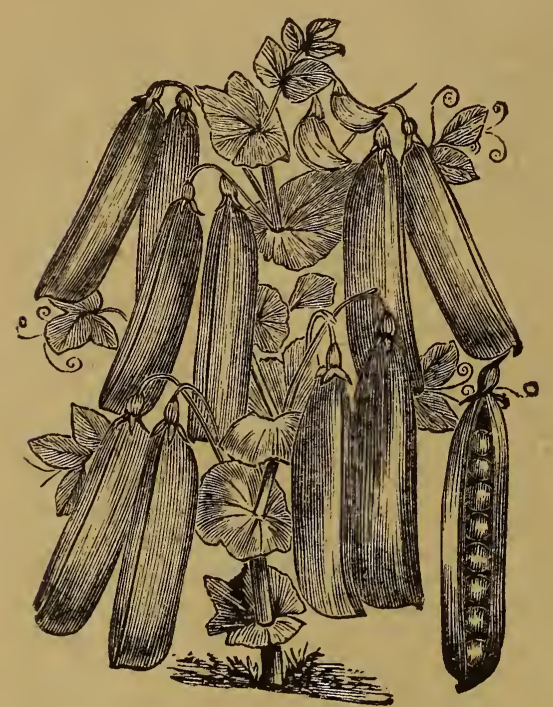

CARTER'S PREMIUM GEM.-This is a valuable wrinkled variety. It is dwarf and robust in habit; produces an abundance of large, well-filled pods and flavor sweet and sugary. Per tb., 30c.

MCLEAN'S LITTLE GEM.-A variety unsurpassed for productiveness and flavor; deșirable for either private or market gardens. Per Ib., 30c.

BLISS' EVERBEARING.-A new wrinkled pea growing about two feet high; it is remarkable in producing large variety. Per tb., 30c.

large variety. Per 1b. $20 \mathrm{c}$.

YORKSHIRE HERO.-A splendid green, wrinkled Marrow pea of branching habit, and an abundant bearer. Height of vine $2 \frac{1}{2}$ feet. Per $1 \mathrm{~b} ., 30 \mathrm{c}$.

LAXTONIAN.-A new, early, dwarf, robust, large podded pea of superior excellence; often referred to as "Dwarf Gradus," and is said to surpass "Gradus" in yield and quality, with the added advantage of dwarfer growth, averaging 16 inches. The large pods are well filled, holding 8 to 10 peas. "Laxtonian" is so highly recommended that you should give it a trial. Per 1b., 30c.

CHAMPION OF ENGLAND.-This is an old popular third early and forms a succession lasting throughout the season and is considered the best pea ever introduced; grows about five feet high. Per lb., 25c.

\section{PEPPERS.}

Peppers should be sown in a hot bed about the middle of March and transplanted to open garden about the middle of May in rows about two feet apart each way or may be sown in open latter part of April and transplanted when large enough to handle. They. require rich soil. An ounce of seed will produce about 500 plants. 


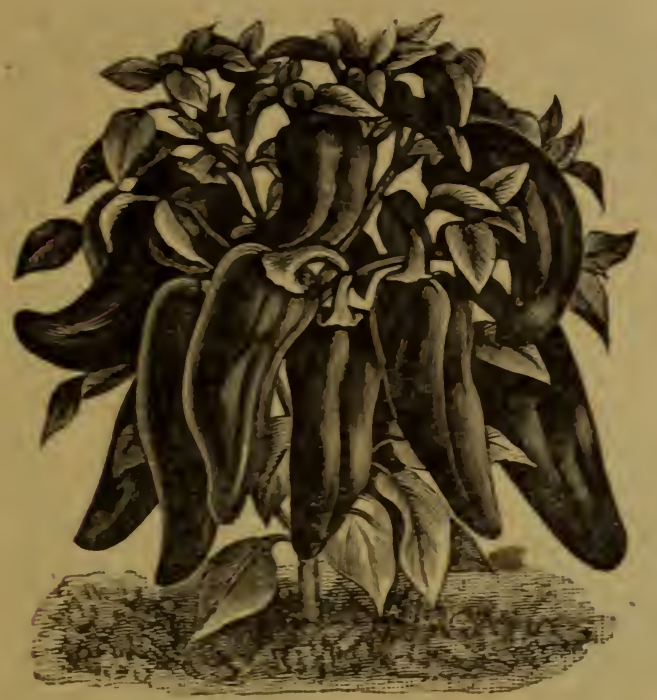

RUBY GIANT.-This is one of the most desirable sorts in cultivation. The peppers grow from four to six inches long by about four inches in thickness. When ripe they are a beautiful ruby red and remarkably mild and pleasant. ly flarored. Per Ib., $\$ 6.00 ; 1 / 4$ Ib., $\$ 1.25$; oz., 60c; pkg., $71 \frac{1}{2} \mathrm{c}$.

\section{BULL NOSE OR LARGE BELL.} -A large sort, of inverting bell shape, suitable for filling or for mixed pickles; flesh thick, hard and less pungent than most sorts. Per Ib., $\$ 6.00$; $1 / 4$ Ib., $\$ 1.25$; oz., $60 \mathrm{c}$; pkg., $7 \frac{1 / 2}{2}$.

GOLDEN QUEEN.-A very large, handsome and productive sort; growing twice the size of Ruby King, thick fleshed and mild flavored. Valuable for filling. Per to., $\$ 5.00 ; 1 \frac{1}{4}$ It ., $\$ 1.25 ;$ oz., 50c; pkg., $7 \frac{1}{2} \mathrm{c}$.

VERY SMALL CAYENNE.-Used in mixed pickles. Per th., $\$ 2.50 ; 1 / 4$ Ib., $\$ 1.00$; oz., $25 \mathrm{c} ;$ pkg., $71 \frac{1}{2} \mathrm{c}$.

CAYENNE.-Fruit about four inches long, of brilliant red color when ripe, very productive, the Cayenne Pepper of commerce. Per $\mathrm{tb} . \$ 3.00 ; 1 / 4 \mathrm{Ib}$. Soc; oz., $25 \mathrm{c}$; pkg., $71 / 2 \mathrm{c}$.

\section{RHUBARB, OR PIE PLANT.}

Propogated by bulbs from old roots, or from seed. To raise seedlings, sow the seed early in spring in rows about two feet apart. then thin to ten inches in the row. To set the seedlings or bulbs from old roots, mark out the ground $3 \times 4$ feet apart in very rich soil and cover plants with manure after being killed down by frost in the fall. One ounce of seed makes about 600 plants.

VICTORIA.-The best variety. Seed per lb. $\$ 1 ; 1 / 4$ lb. $30 \mathrm{c} ; 0 z .15 \mathrm{c} ; \mathrm{pkg}$. $\$ 1.50 ; 1 / 4$ Tb., $45 \mathrm{c} ;$ oz., $15 \mathrm{c}$; pkg., $71 / 2 \mathrm{c}$.

\section{PUMPKINS.}

SWEET POTATO.-Excellent for pies. Pear shand, medium in size; flesh and skin creamy white, fine grained and sweet; good keeper. Per lb. $\$ 1.25 ; 1 / 4$ tb.. $35 \mathrm{c} ;$ oz., $15 \mathrm{c}$; pkg., $71 \frac{12}{2} \mathrm{r}$.

SMALL SUGAR.-A small, orange-colored variety, remarkably sweet, fine grained and dry. Valuable either for baking or making piec. Per lb. $\$ 1.25 ; 1 / 4$ Ib., 35c: oz., $15 \mathrm{c}$; pkg., $71 / 2 \mathrm{c}$. 
MAMMOTH POTIRON.-Also called Ging of Mammoth, Jumbo, etc. Form liks an immense nutmeg melon, with depressed ends; grows to immense size. Skin salmon colored, flesh bright yellow, fine grained and of very good quality. Per tb., $\$ 1.60 ; 1 / 4$ tb., $45 \mathrm{c}$; oz., $15 \mathrm{c}$; pkg., $7 \frac{1}{2} \mathrm{c}$.

KENTUCKY FIELD.-Large, round and a little ribbed; soft shell, salmon color; productive, best for feeding stock. Per tb., $\$ 1.25$; $1 / 4$ tb., $35 \mathrm{c}$; oz., $15 \mathrm{c}$; pkg., $71 / 2 \mathrm{c}$.

CONNECTICUT FIELD.-A large yellow variety, hard shell; is excellent for field culture. Per tb., $\$ 1.25 ; 1 / 4$ tb., $35 \mathrm{c} ; \mathrm{pkg}$., $71 / 2 \mathrm{c}$.

\section{RADISHES}

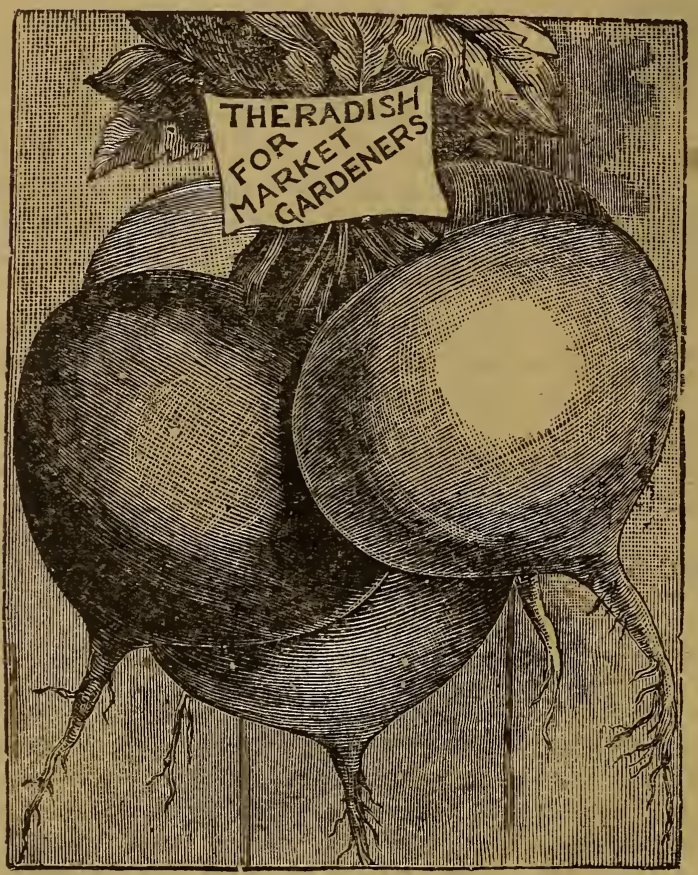

Sow as early as the ground can be worked, in light, rich soil, in rows 12 to 15 inches apart, and every ten days for a succession up to the first of June, after which they are little used. Sow also in early fall for late use. Eight pounds will plant one acre.

EARLY SCARLET GLOBE.This is peculiarly adapted for forcing, having a remarkably small top as compared with other varieties, and small for the size of the radish. The flesh is crisp, tender, and in every way desirable. Per lb. $\$ 1.50$; $1 / 4$ tb., $45 \mathrm{c}$; oz., 15c; pkg., $71 / 2 \mathrm{c}$.

FRENCH BREAKFAST-The standard early radish with market gardeners, one of the first to appear in the market. Scarlet, with white tip; early, oval in shape; brittle, sweet and tender. Per to., $\$ 1.50 ; 1 / 4$ tb., $45 \mathrm{c}$; oz., 15c; pkg., 71/2c.

ICICLE.-A handsome, first class variety, in color, snowy white. It grows to the average length of long varieties, but holds its fulness well down to the tap root. Exceedingly attractive and excellent in every way. Per lb. $\$ 1.75 ; 1 / 4$ Ib., $50 \mathrm{c}$; oz., $15 \mathrm{c}$; pkg., $71 / 2 \mathrm{c}$.

SCARLET TURNIP ROOTED.-A new strain of the old popular variety; verfect in shape; skin dark red, flesh white, with a very small tap root. Per tb., $\$ 1.50 ; 1 / 4$ tb., $45 \mathrm{c}$; oz., $15 \mathrm{c}$; pkg., $7 \frac{1}{2} \mathrm{c}$.

SCARLET OLIVE.-Oblong in shape, flesh rose colored; early and having very small top; valuable for forcing. Per 1b., $\$ 1.50 ; 1 / 4 \mathrm{tb} ., 45 \mathrm{c}$; oz., $15 \mathrm{c}$; pkg., $7 \frac{1}{2} \mathrm{c}$.

CINCINNATI MARKET, OR GLASS.-An improved long, scarlet short top, the roots being more perfect in shape and excellent for forcing. Per lb. $\$ 1.50 ; 1 / 4$ tb., $45 \mathrm{c}$; oz., $15 \mathrm{c}$; pkg., $71 / 2 \mathrm{c}$. 


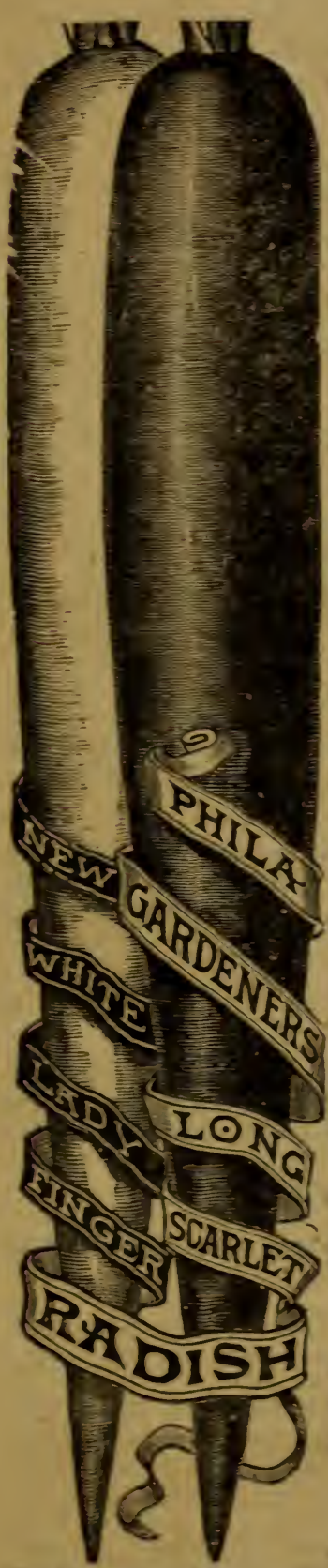

PHILADELPHIA GARDENER'S LONG SCARLET. - This is the very best strain of long scarlet radish, and is the result of years of careful selection. In shape it is shorter and thicker than the old variety and fully a week earlier $w$; ill remain longer in eating condition. The favorite shipping sort. Per $17 . . \$ 1.50 ; 1 / 4$ ID.. $45 \mathrm{c}$ : oz., $15 \mathrm{c}$; pkg., $71 \frac{1}{2} \mathrm{c}$.

EARLY LONG WHITE LADY FINGER.-This is an extra early, large, white, crisp variety, is somewhat shorter than the preceding, and similar in shape; is a very desirable sort, decidedly the best of its kind ever introduced. An admirable sort of peculiar nutty flavor. The seed here offered is from the originators. Per $\mathrm{lb}$ $\$ 1.50 ; 1 / 4$ ID., $45 \mathrm{c} ;$ oz., $15 \mathrm{c}$; pkg., $7{ }_{2}{ }_{2} \mathrm{c}$.

CHARTIER.-A distinct and very handsome and attractive sort. The color of the top is scarlet rose, shading to pure waxy white at the tip. It will attain a very large size before it becomes unfit for the table. remaining crisp and tender for a month or more. A most valuable market sort. Per 1o., $\$ 1.50$; $1 / 4$ ib., $45 \mathrm{c}$ : oz., 15c; pkg., $71 / 2 \mathrm{c}$.

CRIMSON GIANT.-This new radish is excellent for forcing, as well as outdoor growing; the roots attain double the size of other forcing varieties. Per Ib., $\$ 1.75 ; 1 / 4$ ID.. $50 \mathrm{c}$; 0Z., 20c; pkg.. $T^{1 / 2} \mathrm{C}$.

WHITE TIP.-A bright scarlet white tip radish. It has a small top, is a very rapid grower and used exten. sively for forcing. Per to., $\$ 1.50 ; 1 / 4$ to., $45 \mathrm{c}$; oz., $15 \mathrm{c}$; pkg., $71 / 2 \mathrm{c}$.

WHITE STARSBURG.-The roots are of handsome, oblong, tapering shape. Both skin and flesh are pure white. The flesh is firm, brittle and tender, and possessing the most desirable character of retaining its crispness eren when the roots are old and large. It is excellent for summer use, as it stands heat and grows quickly. Per to., $\$ 1.50 ; 1 / 4$ th., $45 \mathrm{c}$; 0z., $15 \mathrm{c}$; pkg., $71 / 2$ c.

CHINA ROSE.-An excellent fall and winter sort, and also grown to some extent as a late summer by gardeners, as it does not get pithy. Crisp throughout the season. Per Ib., $\$ 1.50$; 1/4 Ib., $45 \mathrm{c}$; oz., 15c; pkg.. $71 / 2 \mathrm{c}$.

CALIFORNIA WHITE MAMMOTH.-Very large size, about one foot long and three inches through; flesh pure white, solid. crisp. keeps well through the winter. Per to.. $\$ 1.50$; $1 / 4$ Tb., $45 \mathrm{c}$; oz., $15 \mathrm{c}$; pkg., $71 / 2 \mathrm{c}$. 
LONG BLACK SPANISH.-A winter radish, cultivated in autumn and keeping like a potato in good condition for months after harvesting. Though the outside is black, the flesh is white as snow; very crisp and a good flavor. Per tb., $\$ 1.35 ; 1 / 4$ tb., 40c; oz., 15c; pkg., $7 \frac{1}{2} \mathrm{c}$.

\section{SALSIFY, OR OYSTER PLANT.}

The oyster plant will do well on any land suitable for parsnips. The soil should be deeply plowed or dug, and finely pulverized. Sow in drills 18 inches apart about $1 \frac{1}{2}$ inches deep, and thin to 2 inches apart in the row. This vegetable closely resembles the oyster in flavor, and is used in either soup, dressed plain or boiled and fried. One ounce will sow sixty feet of rows.

SANDWICH ISLAND MAMMOTH.-This new variety produces roots double the size and weight of Long White and of equal quality and flavor. Per tb., $\$ 3.00 ; 1 / 4$ tb., $85 \mathrm{c}$; oz. $30 \mathrm{c}$.

\section{SPINACH.}

For early spring use sow about the first of October in highly manured soil. It usually stands winters without protection, and is ready for use as soon as the ground is open in the spring.

NEW VICTORIA.-Quick to mature; forms very large, exceedingly thick leaves, savoyed-in the center. It remains in condition for use much longer than most kinds, and cannot fail to please. Per tb. $\$ 1.50 ; 1 / 4$ tb. $50 \mathrm{c}$; oz., 10c; pkg., $71 / 2 \mathrm{c}$.

SAVOY LEAVED.-In appearance the leaves are wrinkled in much the same way peculiar to Savoy cabbage, hence the name-under the same conditions it produces twice the bulk of crops as the ordinary sort; it is fully as hardy and in every way desirable. Per tb., $\$ 1.00$; $1 / 4$ tb., $35 \mathrm{c} ;$ pkg., $71 / 2 \mathrm{c}$.

\section{SQUASH.}

Squashes require soil in fair state of fertility. The season for planting varies, of course, with the locality. A fair guide is to plant when the apple is in blossom, and possibly three weeks later for late sorts. Plant $4 \times 4$ feet for the bush or early varieties, and $6 \times 8$ feet for the long running sorts. About two lbs. of bush and four lbs. of large seeded kinds per acre.

EARLY WHITE BUSH.-An early scalloped-shaped sort, skin light cream colored. Per tb., $\$ 1.25$; $1 / 4$ tb., $35 \mathrm{c}$; oz., $10 \mathrm{c}$; pkg., $71 / 2 \mathrm{c}$.

EARLY SUMMER CROOKNECK.-Plant dwarf, compact, fruit deep yellow; one of the best early varieties. Per tb., $\$ 1.25 ; 1 / 4 \mathrm{tb} ., 35 \mathrm{c} ; 0 \mathrm{z} ., 15 \mathrm{c}$; pkg.,

ESSEX HYBRID.-One of the finest grained, richest flavored, most prolific and sweetest of the squash family; ripens early and keeps until spring. Flesh very rich orange color, dry and solid. Per 1b., $\$ 1.35 ; 1 / 4$ tb., $40 \mathrm{c}$; oz., $15 \mathrm{c}$; pkg., $71 / 2 \mathrm{c}$.

BOSTON MARROW.-The earliest of the fall sorts; is ready for use soon after the summer varieties. Rich orange color, good size, excellent flavor. Per tb., $\$ 1.35 ; 1 / 4$ tb., $40 \mathrm{c}$; oz., $15 \mathrm{c}$; pkg., $71 / 2 \mathrm{c}$. 


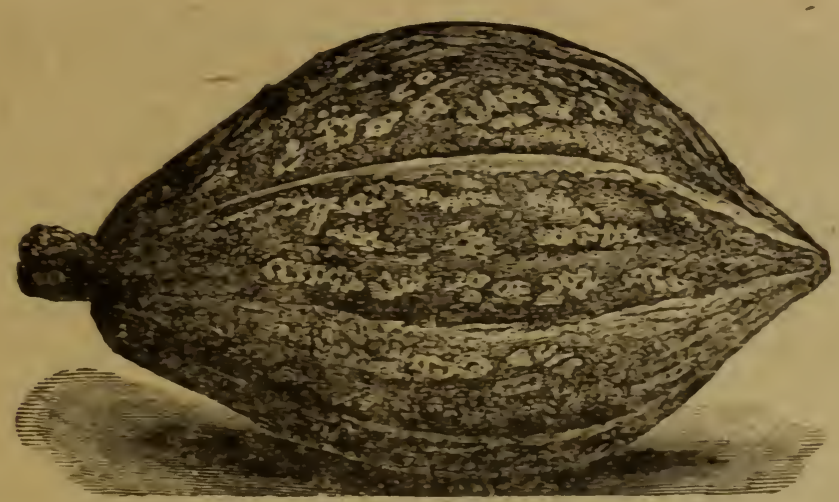

MAMMOTH CHILI.-The largest of Spanish family, often weighing 200 pounds or over. Flesh a rich orange yellow, very thick and of fair quality; very nutritious and profitable for feeding stock. Per Ito., $\$ 1.50$ : 1/4 to.. $45 \mathrm{c}$; oz., $15 \mathrm{c}$; pkg.. $71 / 2 \mathrm{c}$.

NEST EGG.-Grows exactly in size and color the shape of an egg; will not crack and are uninjured by cold or wet. They make the very best nest eggs. The plant is a handsome and rapid growing climber, and very ornamental for corering screens, arbors, etc. We have the true variety, which heretobefore has been very difficult to obtain. Per pkg. 10c.

HUBBARD.-This has long been the leading winter squash; hard shelled, good keeper, flesh dark yellow, fine grained, dry and sweet. Per tb., \$1.35; $1 / 4$ tb., 40c; 0z., 15c; pkg., $71 / 2 \mathrm{c}$.

DIPPER.-Named from its semblance in shape to a dipper. The capacity varies from a pint to a quart, with handles from 2 to 12 inches long. They are easily prepared for use as dippers and will last for years. Are conrenient for dipping hot liquids, as the handle don't heat through. Useful for farm and household purposes. Per lb. $\$ 2.40 ; 1 / 4$ lb. $70 \mathrm{c} ; 0 \mathrm{z} .25 \mathrm{c} ; \mathrm{pkg} .10 \mathrm{c}$.

FORDHOOK.-A new winter squash of excellent variety for winter use, the flesh is dry and sweet, and it seems incapable of rotting. Ripens early, and is well adapted to the north. Per tb., $\$ 1.35 ; 1 / 41 \mathrm{tb} ., 40 \mathrm{c} ; 0 \mathrm{z} ., 20 \mathrm{c} ; \mathrm{pkg} .71 / 2 \mathrm{c}$.

\section{TOMATOES.}

For early fruit the seed should be sown in a hotbed about the first week in March, in drills fire inches apart and one-half inch deep. Sufficient plants for a small garden may be started by sowing a few seed in a shallow box or flower pot, and placing them in a window of the house. When the plants are three or four inches high they should be set out four or five inches apart in another hotbed or cold frame, or put into small pots, one plant in each pot; expose to the air as much as possible to harden. Water freely at time of transplanting, and shelter from the sun a few days until the plants are established. Cultirate thoroughly as long as the vines will permit. Tomatoes admit of training upon poles or trellises of various kinds, and the fruit 


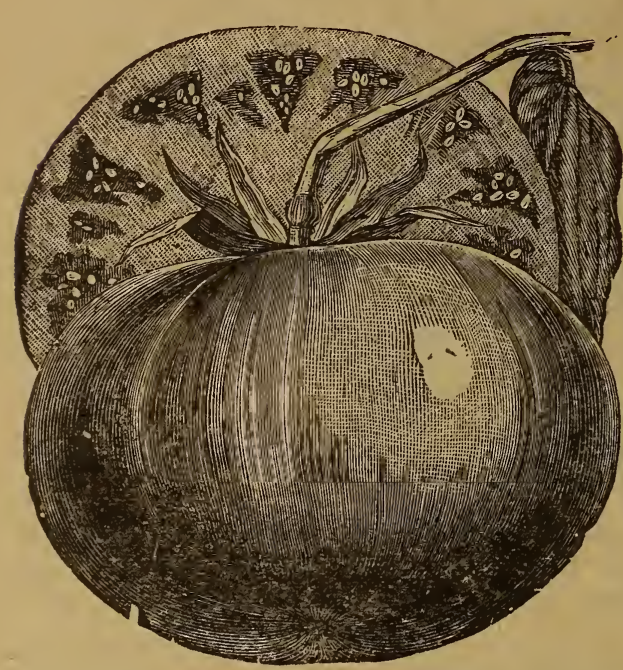

is much improved both in appearance and quality. The usual method is to set one strong plant to a stake five to seven feet high, tying the plant with soft material and pruning freely as the plant advances in growth: By adopting this plan the plants may be set much closer together than in the ordinary way. Ordinarily they are planted in rows four feet apart and plants set from three to four feet in the row. The time for transplanting to open ground, when the danger of frost is over. One ounce of seed will produce 1000 plants.

EARLINA.-(New). The earliest, large, smooth, red tomato. This tomato is not only remarkable for its earliness, but for its very large size, handsome shape and bright color. Its solidity and fine quality are equal to the hest medium and large sorts. From less than 4000 hills the originator realized from his first pickings $\$ 725.00$ clear of freight and commission, being in the market fully a week before all others. Per 1b., $\$ 3.00 ; 1 / 4$ tb., $90 \mathrm{c}$; oz., $30 \mathrm{c}$; pkg., $71 / 2 \mathrm{c}$.

DWARF CHAMPION.-This is a distinct and valuable sort. The plants grow two feet high, the branches are short, making the plant bushy, which stands quite erect. The foliage has quite a corrugated appearance, and is of very remarkable green color. It is early and very prolific. The fruit is a dark purplish red, of medium size, perfectly round and smooth, and contains but few seeds and is very solid and heavy. Per tb., $\$ 2.50 ; 1 / 4 ., 75 \mathrm{c}$; oz., 30c; pkg., $71 / 2 \mathrm{c}$.

ACME.-There is probably no variety so well known and generally cultivated, both for main and early crops. The plants are strong and vigorous and very productive; fruit of medium size, perfect form, round and very smooth and handsome. Color a glossy red with purplish tinge; ripens all over and through at the same time. Per $1 \mathrm{~b} ., \$ 2.50 ; 1 / 4 \mathrm{lb} ., 75 \mathrm{c} ;$ oz., $30 \mathrm{c}$; pkg.,

TROPHY IMPROVED.-Well known as one of the best. Vines of medium size, both producing compact clusters of fruit in immense quantities; fruit large, $($ smooth and of bright red color. Per $1 \mathrm{tb} ., \$ 2.25 ; 1 / 4 \mathrm{tb} ., 75 \mathrm{c}$; oz., $30 \mathrm{c}$; pkg., $71 / 2 \mathrm{c}$.

THE STONE.-Very large, perfectly smooth and thicker from stem to blossom end than most varieties, making it very handsome and saleable. Color beautiful red, is an excellent shipper, quality excellent, ripening throughout without hard core, and not subject to rot. Per $1 \mathrm{~b} . \$ 2.50 ; 1 / 4 \mathrm{lb}$. $75 \mathrm{c}$; oz., 30c; pkg., $71 / 2 \mathrm{c}$.

PEAR-SHAPED YELLOW.-Used for pickles and preserves; very productive and excellent for the above purposes. Per oz., 30c; pkg., 71/2c. 


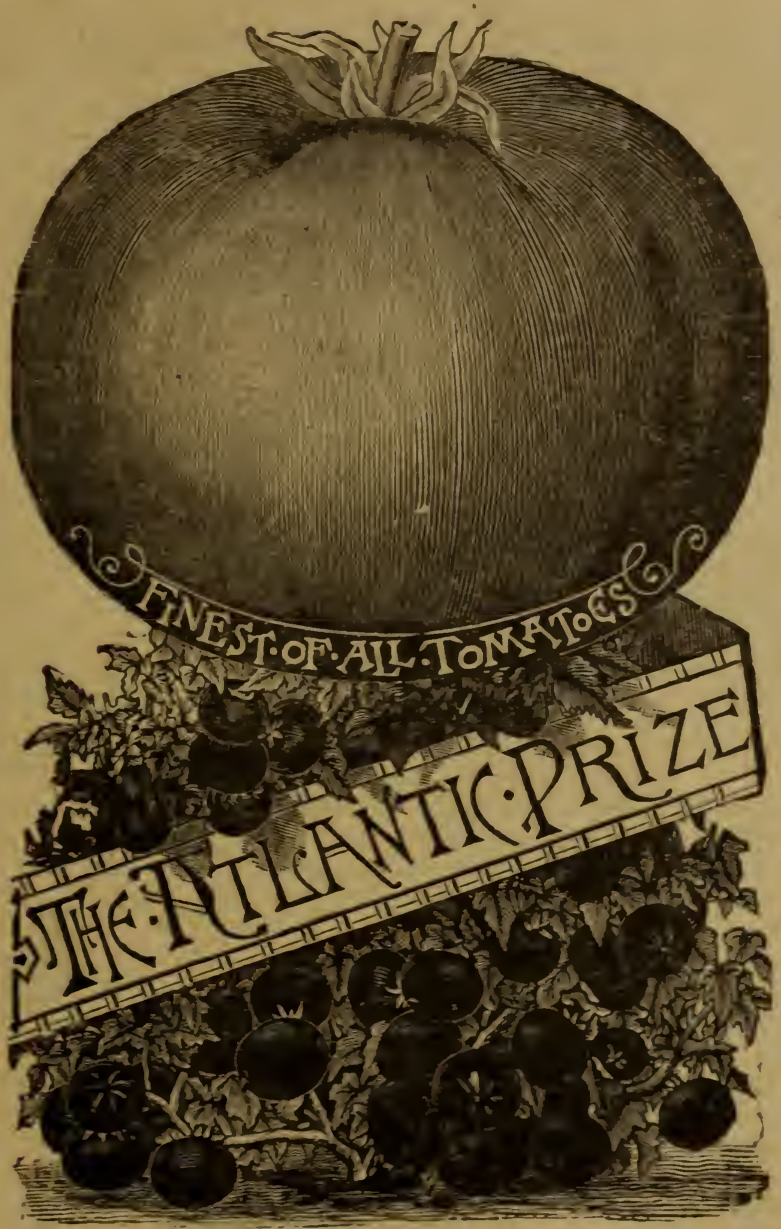

ATLANTIC PRIZE.-While this sort has been in cultivation for years, I have as yet found nothing so valuable for the market gardener as this famous variety. The vines grow strong, stiff and very rapidly, setting the crown buds while the plants are yet very small. The vines have comparatively few leaves; are very hardy, bear the fruit low down on the stem and in enormous quantities. It is of fair size, deep red in color, fine flavor and VERY EARLY. Per th., $\$ 2.50$; $1 / 4$ id., $75 \mathrm{C} ; 0 z ., 30 \mathrm{c} ; \mathrm{pkg}$., $71 \frac{1}{2} \mathrm{C}$.

LIVINGSTON BEAUTY.-This variety contains about all the good qualities found in the tomato family. It is quite early, hardy, a strong grower, productive, large in size, always smooth, flesh solid and of excellent quality. In color it is a very glossy crimson with a slight tinge of purple. It grows in culsters of four or five large fruits, retaining its large size late in the season. It ripens with Acme, and in shape it is perfect. The skin is quite thick and is seldom cracked after a rain, like the thin skinned sorts. Per $1 \mathrm{~b}$. $\$ 2.50 ; 1 / 4$ Bo., 75c; oz., $30 \mathrm{c}$; pkg., $71 \frac{1}{2} \mathrm{c}$. 
LIVINGSTON'S FAVORITE.-This is a popular sort. It ripens evenly and quite early; is very productive. The fruit is large, smooth and very handsome; color red. It is free from cracks and does not rot at the blossom ends; a first class shipper. Per tb., $\$ 2.50$; $1 / 4$ tb., $75 \mathrm{c}$; oz., $30 \mathrm{c}$; pkg., $71 / 2 \mathrm{c}$.

LIVINGSTON'S PERFECTION.-Mr. Livington claims this is an im. proved Acme with a red skin, somewhat larger, fully as early. has more solid flesh and fewer seeds; produces more and larger fruit at the close of the season. It is pefectly smooth and of a handsome blood-red color. Per $\mathrm{lb}$. $\$ 2.50 ; 1 / 4$ tb., $75 \mathrm{c}$; oz., $30 \mathrm{c}$; pkg., $7 \frac{1}{2} \mathrm{c}$.

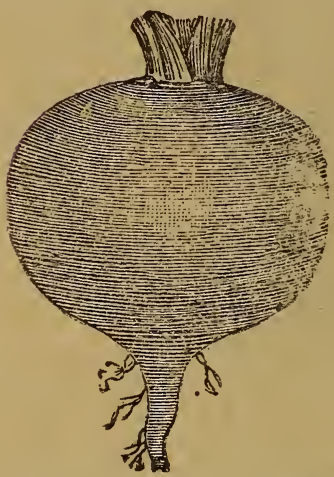

\section{, TURNIPŚ.}

For early, sow as soon as the ground can be worked, in drills 15 to 18 inches apart, and half an inch deep. Thin to six inches in the row. Turnips will grow on any soil that is moderately rich. An essential point is to make them grow quickly, otherwise they are apt to be tough and woody. They do best in light, loamy soil, that which has been manured for a previous crop is preferable to manuring with stable manure at time of sowing as in this case they are liable to be wormeaten, hence unsaleable. Two pounds will plant an acre.

WHITE MILAN.-The earliest of all. Among the unexcelled earliness and its beautiful shape. It is so smooth and neat as to look polished by hand, and the scant short (entire) foliage forms a becoming ornament to the rine root. Per $1 \mathrm{~b} ., \quad \$ 2.00 ; 1 / 4$ 1b., $60 \mathrm{c}$; oz., $20 \mathrm{c} ;$ pkg., $7 \frac{1}{2} \mathrm{c}$.

EXTRA EARLY PURPLE TOP MILAN.-This sort is the earliest, the handsomest flat turnip in cultivation. The tops are small, strap-leaved, growing erect and compact. The roots are very white, with clear purple top. The most desirable early sort. Per lb. $\$ 2.75 ; 1 / 4$ th., $80 \mathrm{c}$; oz., $25 \mathrm{c}$; pkg., $71 / 2 \mathrm{c}$.

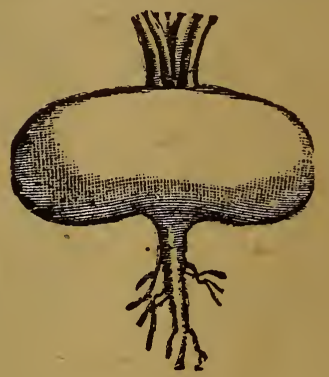

FLAT DUTCH.-This is the popular early turnip for table use. Quick growth and very sweet and tender. Per tb., $\$ 1.75 ; 1 / 416 ., 50 \mathrm{c} ;$ oz., $20 \mathrm{c}$; pkg., $71 / 2 \mathrm{c}$.

EARLY SNOWBALL.-A variety of rapid growth, fine grained, sweet and crisp. Per tb., $\$ 1.75 ; 1 / 4$ tb., 50c; oz., $20 \mathrm{c}$; pkg., $7 \frac{1}{2} \mathrm{c}$.

LARGE RED TOP GLOBE.-A variety of recent introduction, a little later than the preceding, but a much heavier cropper; quality unsurpassed. Per tb., $\$ 1.75$; $1 / 4$ tb., $50 \mathrm{c}$; oz., $20 \mathrm{c}$; pkg., $71 / 2 \mathrm{c}$.

NEW WHITE EGG.-This sort belongs to the class of quick growing fall turnips, and should be sown about August 1st; it is very mild and sweet; one of the best for table use. Per 1b., $\$ 1.50 ; 1 / 4$ tb., $50 \mathrm{c}$; oz., $15 \mathrm{c}$; pkg., $71 / 2 \mathrm{c}$.

GOLDEN BALL.-Among the most delicate and sweetest yellow fleshed turnips yet produced. Not of large size, but firm, hard and of most excellent flavor. Keeps well. Per tb., $\$ 1.75 ; 1 / 4 \mathrm{tb}$., 50c; oz., $20 \mathrm{c}$; pkg., $71 / 2 \mathrm{c}$.

POMERANIAN GLOBE.-A free growing variety, though not of so rapid flavor. Keeps well. Per 1b., $\$ 1.50 ; 1 / 4$ tb., 50c; oz., 20c; pkg., $71 / 2 \mathrm{c}$. 
AMBER GLOBE.-Strap-leaved. A splendid fall and winter variety, of a pale yellow color, sweet and fine in flavor; does not grow pithy. Per to. $\$ 1.50 ; 1 / 4$ ID., $50 \mathrm{c}$; oz., $20 \mathrm{c}$; pkg., $71 / 2 \mathrm{c}$.

YELLOW ABERDEEN, OR SCOTCH YELLOW.-This is a highly esteemed variety, attaining a very large size; it is solid, a good keeper and reliable in every respect. Per ID., $\$ 1.50 ; 1 / 4$ to., $50 \mathrm{c} ;$ oz., $20 \mathrm{c} ; \mathrm{pkg} ., 71 / 2 \mathrm{c}$.

SNOW WHITE GLOBE.-This is one of the most desirable sorts grown for late summer use or keeping through winter for early spring. It will keep as well as a rutabaga and is very much more desirable. Per $\mathrm{Ib}$., $\$ 1.50 ; 1 / 4$ Ib., $50 \mathrm{c} ;$ Oz., 20 ; pkg., $71 / 2 \mathrm{c}$.

IMPROVED AMERICAN.-The leading variety; very hardy and productive; flesh yellow, solid and very fine flavor. Per Io., $\$ 2.25 ; 1 / 4 \mathrm{~Tb} ., 65 \mathrm{c}$; oz., $20 \mathrm{c}$; ukg., $71 / 2 \mathrm{c}$.

LARGE WHITE.-This variety differs from the yellow only in color, the flesh being white; it possesses all the good qualities of the yellow and is preferred by some on account of the color. Per lb., \$2.25; $1 / 4$ Ib., 65c; oz., $20 \mathrm{c}$. pkg., $71 / 2 \mathrm{c}$.

PRIZE WINNER.-The claims to merit of this high grade Rutabaga are: A short neck, large size, smoothness and symmerty of form, and great productiveness of marketable tubers. Per to., $\$ 2.25$; $1 / 4$ to., $60 \mathrm{c} ;$ oz., $20 \mathrm{c}$; pkg., $71 / 2 \mathrm{c}$.

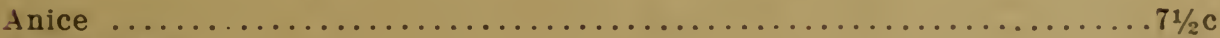

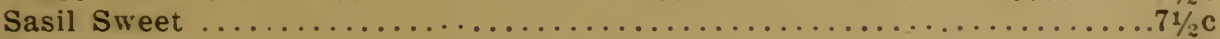

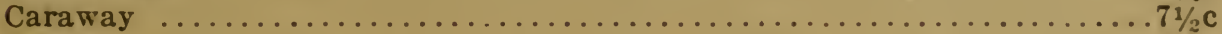

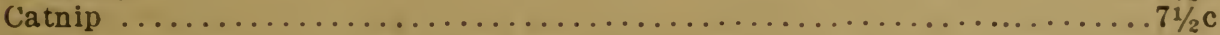

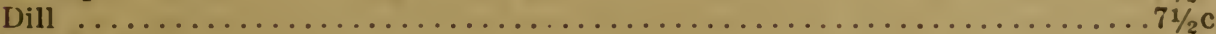

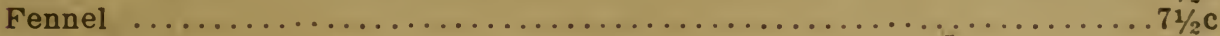

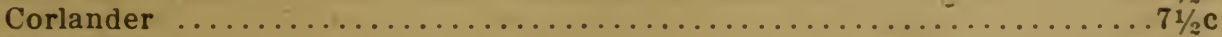

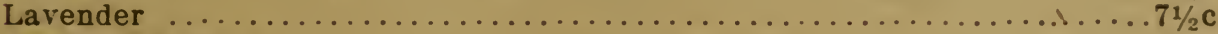

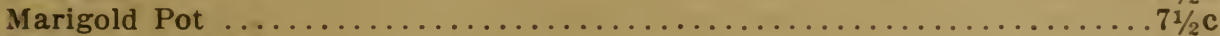

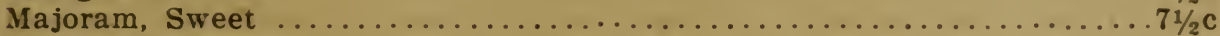

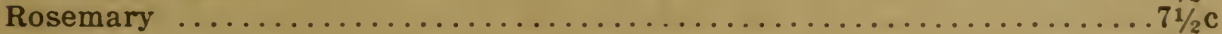

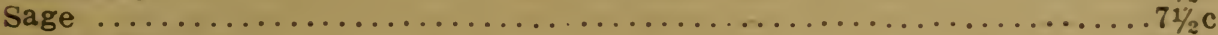

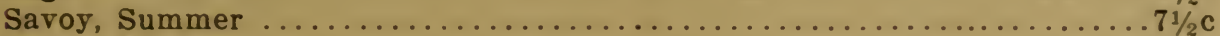

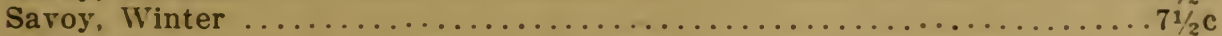

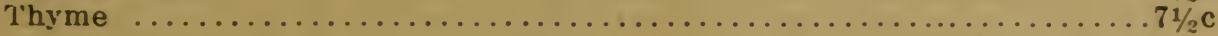

TOBACCO.

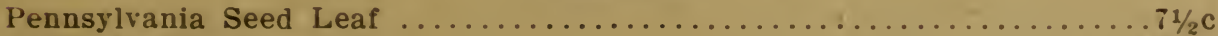

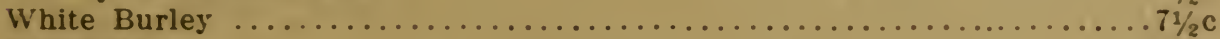

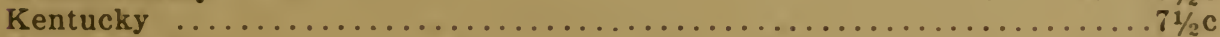

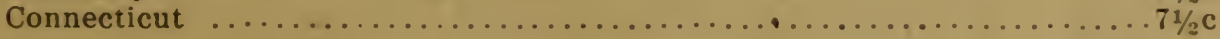

TREE SEEDS.

If to go by mail, add parcel postage.

Honey Locust, per acre 2 pounds ......................... pound $\$ .50$

Black Locust, per acre 1 pound .......................... per pound .50

Catalpa Speciosa (Hardy Satalpa), per acre $1 / 2$ pound.........Per pound 1.50

Russian Mulberry, per acre $1-8$ pound ..................... per pound 3.00 
MISCELLANEOUS SEEDS, ETC.

In ordering add parcel postage.

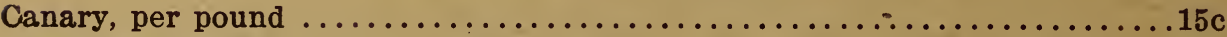

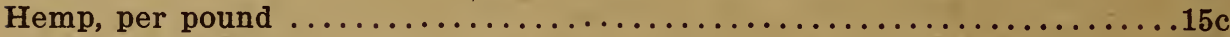

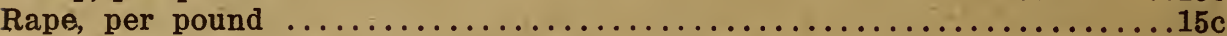

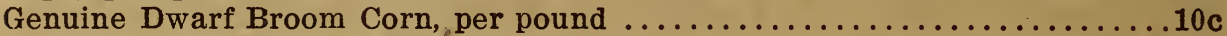

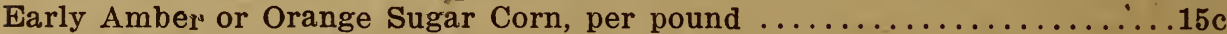

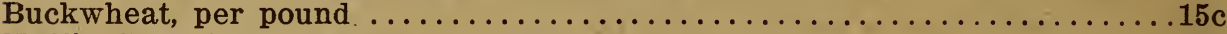

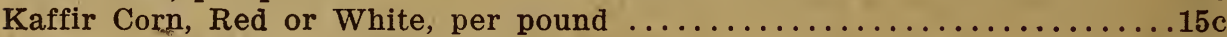

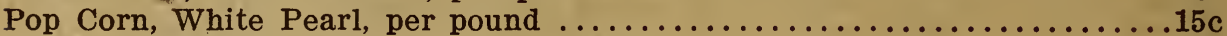

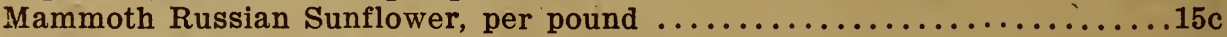

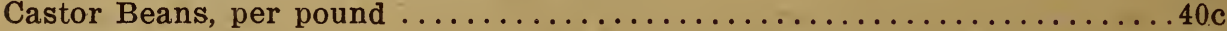

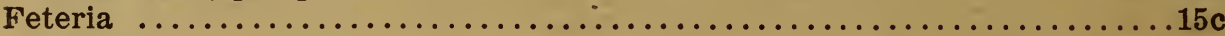

-

GRASS SEED.

Add postage, is to be sent by mail.

In grass seeds there are three grades, viz: Choice, prime and ordinary. The prices here are for the choicest quality, and should not be confounded with the cheaper prices of some catalogues. Inferior seeds can be furnished, if desired, at much lower prices than those given you. Owing to the constant change in the prices of grass seed, can only give you the prices at the time this catalogue goes to press. If lower at the time of ordering, I will send more seed; if higher, less.

CRIMSON CLOVER.-This is an annual plant, and can be sown at all seasons; used principally for plowing under as green manure. Per $100 \mathrm{lbs}$. $\$ 30.00$; per $1 \mathrm{~b} ., 35 \mathrm{c}$.

RUSSIAN FORAGE GRASS.-This has been grown in several localities on light, dry soil, with excellent results, and will produce more hay on our common foothill land than can be grown of timothy on best bottoms. Can be sown at all seasons. Per 100 tbs., $\$ 30.00$.

SUDAN GRASS.-Is strictly an annual like millet. It is best sown broadcast or with drill; cut with a mower like other hay. It grows from three to five feet high. Sow about corn planting time when the ground is warm. This is a dry land grass and will grow with less moisture than most anything else. In the dry land of Texas they claim it yields three tons to the acre. Sow from 10 to 15 pounds per acre. Per 1b. $30 \mathrm{c} ; 100$ ibs. $\$ 30.00$.

FINE LAWN GRASS MIXTURE.-A combination of grasses producing an extra fine velvety lawn. Per $100 \mathrm{lbs}$. $\$ 35$; per $1 \mathrm{~b}$. 40c.

Alfalfa, market price, about $\$ 26.00$ per $100 \mathrm{lbs}$. Write for prices.

Alfalfa, Turkishtan or dry land, per $100 \mathrm{tb}$ s. $\$ 25.00$; per $1 \mathrm{~b} .30 \mathrm{c}$.

Red Clover, fancy, per 100 tbs., $\$ 48.00$; per tb., 50c.

White Clover, fancy, per 100 tbs. $\$ 50.00$; per to $60 \mathrm{c}$.

Timothy, per $100 \mathrm{tb} b s ., \$ 15.00$; per tb., $17 \mathrm{c}$.

Kentucky Blue Grass, fancy, per 100 tbs. $\$ 35.00$; per to. $40 \mathrm{c}$.

Red Top, per $100 \mathrm{lbs}$. $\$ 20.00$; per 1b. 25c.

Johnson's Grass (Evergreen Millet) per 100 ibs. $\$ 18.00$; per Ib. $20 \mathrm{c}$.

German Millet, per $100 \mathrm{lbs}$. $\$ 8.00$; per 1b. $10 \mathrm{c}$.

Hungarian Millet, per $100 \mathrm{lbs} . \$ 8.00$; per 1b. $10 \mathrm{c}$.

Tall Meadow Oat Grass, per 100 tbs., $\$ 33.00$; per th., $35 \mathrm{c}$.

Orchard Grass, per 100 ths., $\$ 33.00$; per th., $35 \mathrm{c}$. 


\section{FLOWER SEEDS.}

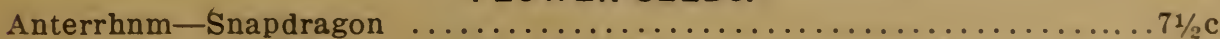

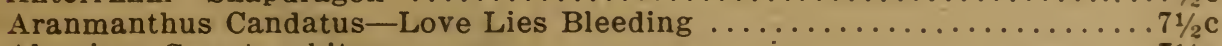

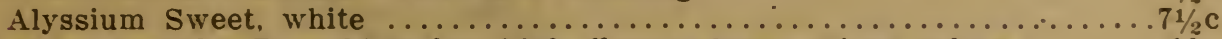

Aster, Semples Branching, feet high, flowers large, mixed colors..........10

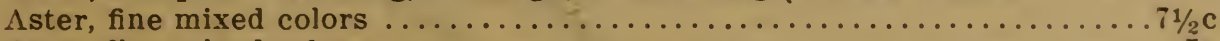

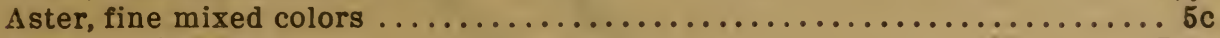

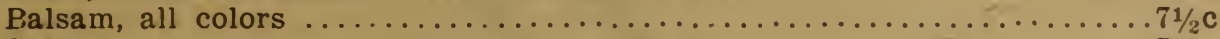

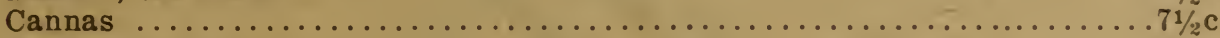

Canterbury Bell ................................

Convolvus Morning Glory . . . . . . . . . . . . . . . . . . .

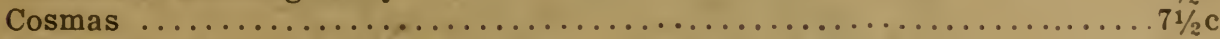

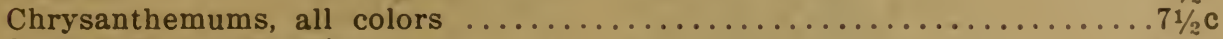

Candytuft, dwarf white .........................

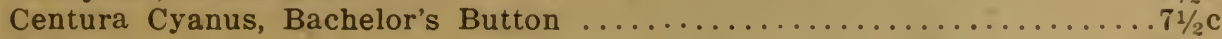

Calliapsis ...........................

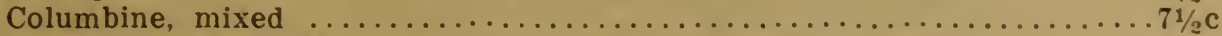

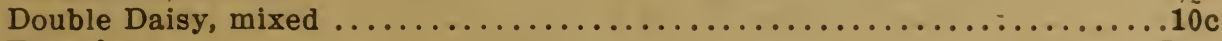

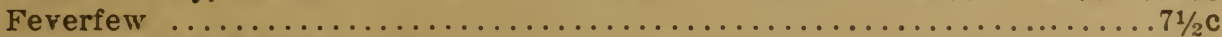

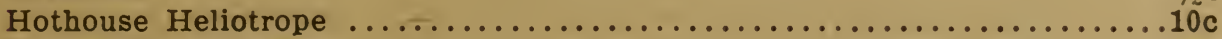

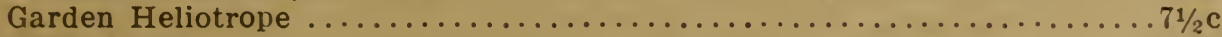

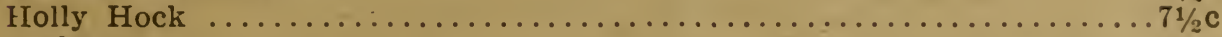

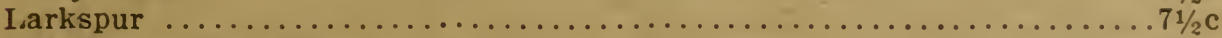

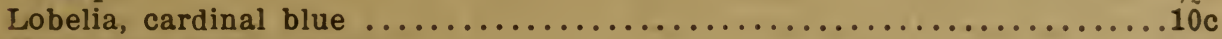

Mignonete, golden, white ......................... $71 / 2 \mathrm{c}$

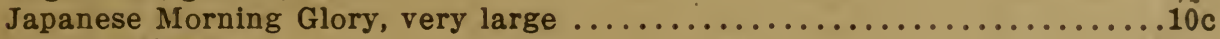

Poppy, Mikado ...............................

Poppy, California .................... $71 / 2 \mathrm{c}$

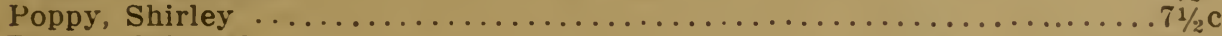

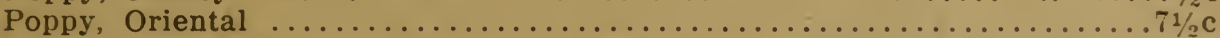

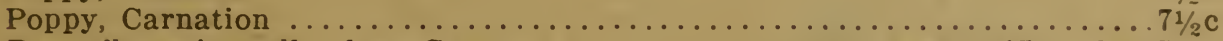

Peas, flowering, all colors, Spencer ............... per oz. $15 \mathrm{c}$; pkg. $71 / 2 \mathrm{c}$

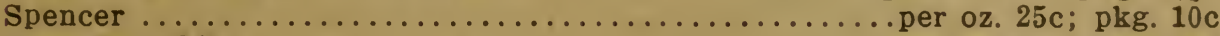

Spencer, white ................................ oz. 25c; pkg. 10c

Spencer, Light Pink ............................... $02.25 \mathrm{c}$; pkg. $10 \mathrm{c}$

Spencer, Red ................................... oz. 25c; pkg. 10c

Spencer, Maroon .................................. oz. 25c; pkg. 10c

Spencer, Lavender ............................ per oz. 15c; pkg. 10c

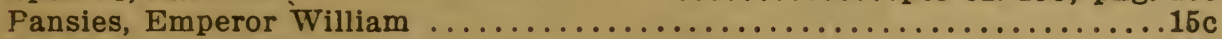

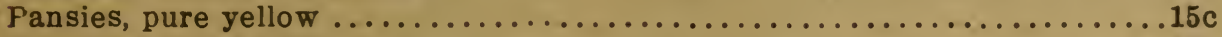

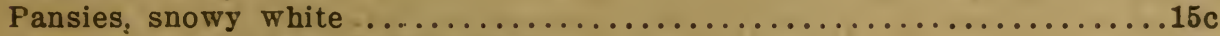

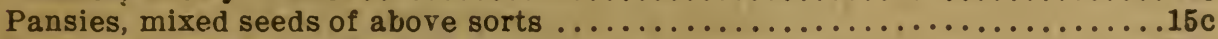

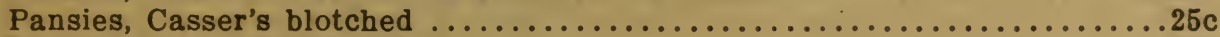

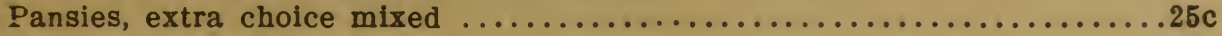

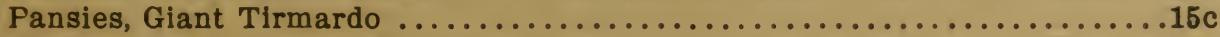

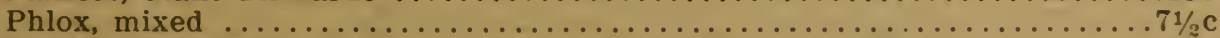

Portulacca, mixed .......................

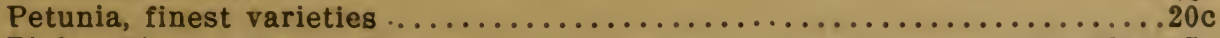

Pinks, mixed colors ............................... $5 \mathrm{c}$

Finks, Carnations, double fiery scarlet .................... per pkg. 10c

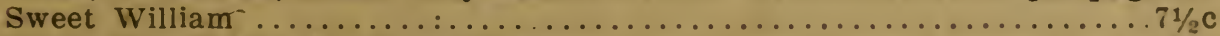

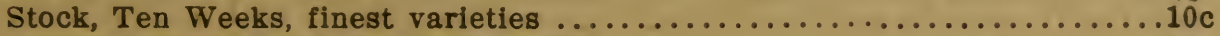

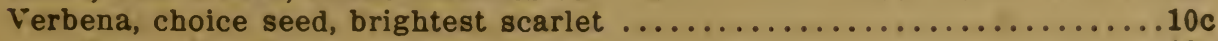

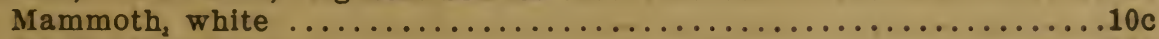

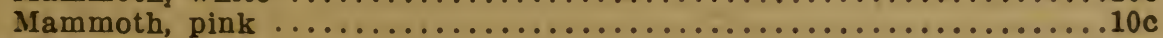

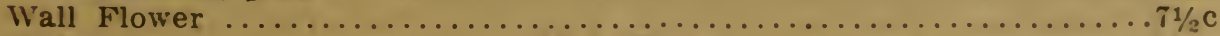

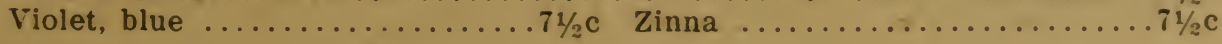




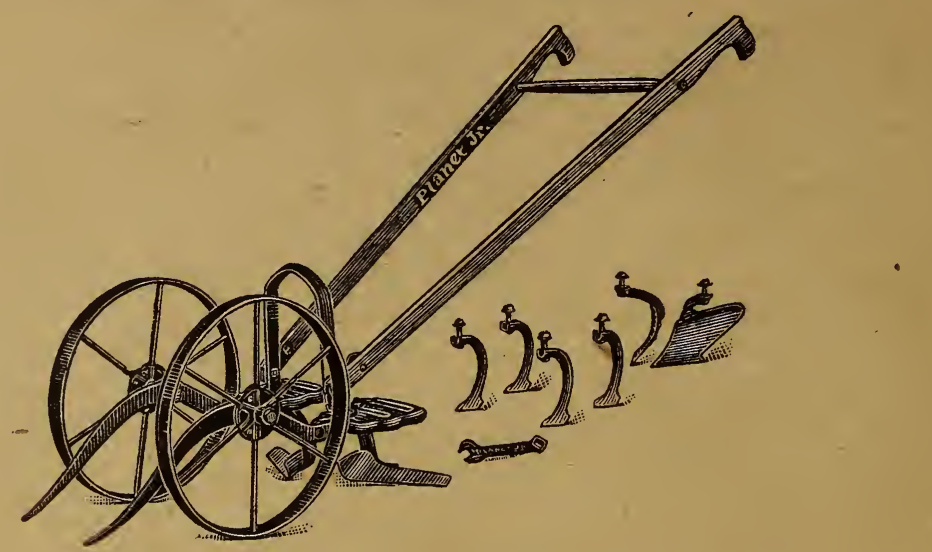

No. 12 Double Wheel Hoe, Cultivator, Rake and Plow.

Price, with attachments as in cut, $\$ 10.00$

DOUBLE WHEEL HOES.-Planet J. double wheel hoes are the greatest tools in the world for the onion grower. They do more work and do it better and easier than can possibly be done in any other way. They represent the highest perfection in every detail. Price $\$ 13.25$.

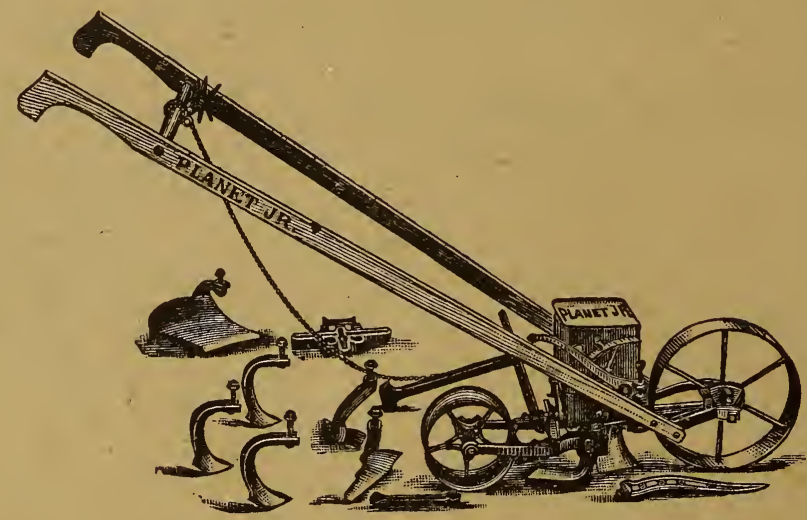

No. 4 Combined Drill and Wheel Hoe.

This is a very popular tool and friends have been gained by its merit alone. As a seed-sower it is identical with No. 2 Drill except in size, and has all of its merits, its strength, durability, ease of operation and perfection of work. The combined tool has a complete set of cultivating tools, and all its operations are rapid and easy. When used as a drill the seed is sown with great regularity and at uniform depths, regulated at pleasure. The index contains the names of the principal seeds, and when the name wanted appears through the index slot, it is right for that seed. Price complete, $\$ 20.25$. Plain, \$16.25. 


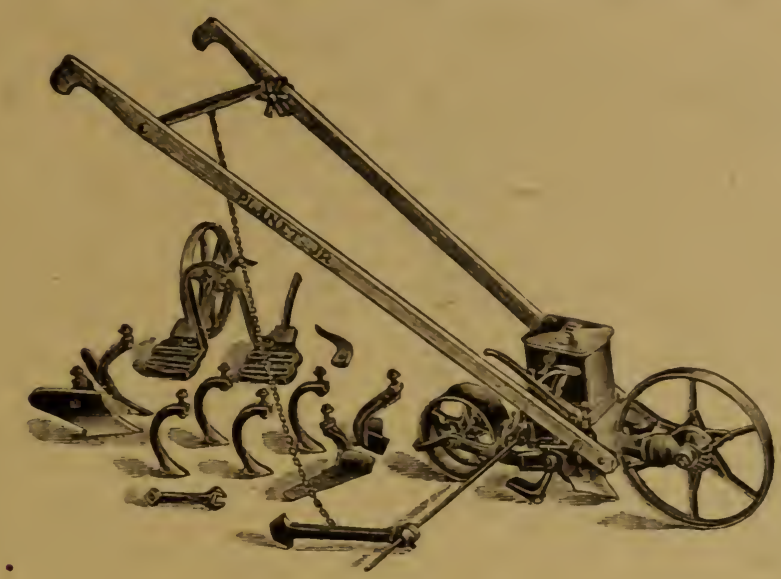

\section{No. 25 Combined Hill and Drill Seeder and Double Wheel Hoe Cultivator and} Plow.

This new combined machine is intended for a class of gardens which have a large enough acreage in crops for a double wheel hoe to be used ta good advantage, and yet prefer not to buy a separate wheel hoe. It is large enough for field use, for it holds $2 \frac{1}{2}$ quarts (or about five pounds of onion seed) and has $11 \frac{1}{2}$-inch wheels-which are just the right size.

As a drill it is almost identical with the Planet Jr. No. 4 Drill; will sow in drills or hills, 4, 6, 8, 12 or 24 inches apart, and has the same feed, hill dropping mechanism and automatic device for throwing out of gear and the new combined cutoff and seed index with the brass thumbscrew adjustment. It is thoroughly substantial and is accurate in sowing all kinds of garden seeds in either hills or drills.

As a wheel hoe it is identical with the Planet Jr. No. 12 Double Wheel Hoe, the very best machine on the market; the change from drill to-wheel hoe and back again is quickly made and the entire combination is one we heartily recommend and guarantee satisfactory.

The simplicity and perfect working of this tool, both as a seeder and as a wheel hoe, make the combination thoroughly practical. No worrying chains and top-lofty weak wire wheels deceive the unwary here.

The accuracy of the seeder in sowing all varieties of garden seeds, whether in hills or drills, and the adaptability of the wheel hoe to various hinds of garden and field work, make such a combination almost impossible to surpass. Price complete, $\$ 23.75$. 


\section{USEFUL TABLES.}

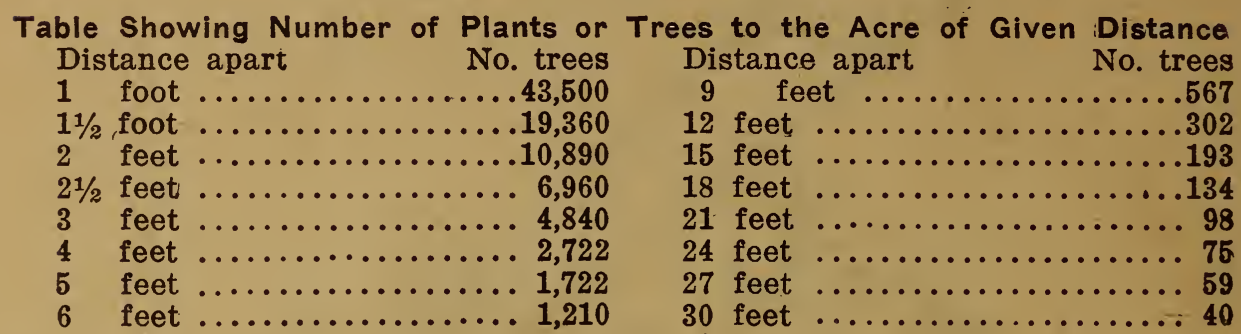

Quantity of Seed Required for a Given Number of Plants

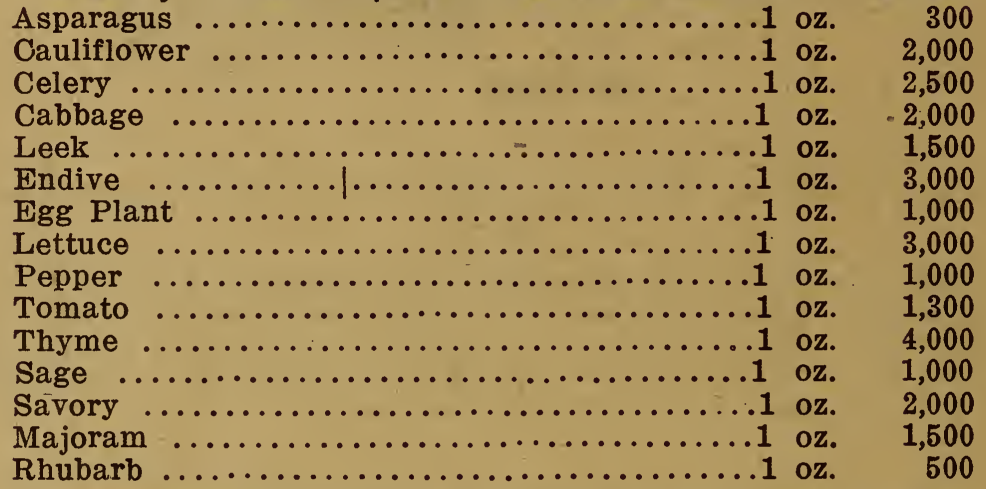

Weights Per Bushel and Amounts of Seed Sown Per Acre.

No. Lbs. No. Lbs.

per Bus. to Acre.

Alfalfa Clover .................60

Red Clover ..................60

White Clover ................60

Alsike Clover ...................60

Timothy ............................

Blue Grass .........................

Red Top ........................

Mixed Grasses ......................

English Rye Grass ..................

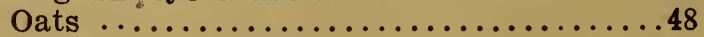

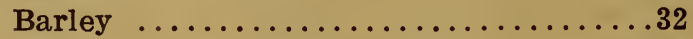

Corn ...........................

Orchard Grass .....................

Hungarian .......................

Common Millet .......................

German Millet ....................

Hemp ..........................

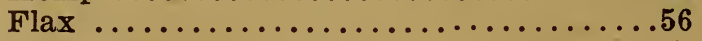

Buckwheat ........................

Rye .......................

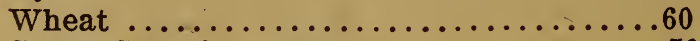

Sugar Cane for Fodder ..............

20 to 30

12 to 15

6 to 8

6 to 8

10. to 15

30 to 40

20 to 30

30 to 40

15 to 25

60 to 90

32 to 64

8 to 12

20 to 30

28 to 25

25 to 40

25 to 40

35 to 55

30 to 40

25 to 52

60 to 90

60 to 90

60 to 100 


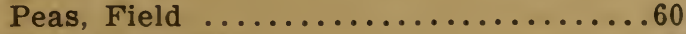

90 to 100

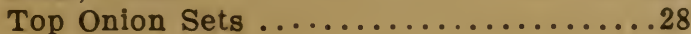

In Drills.

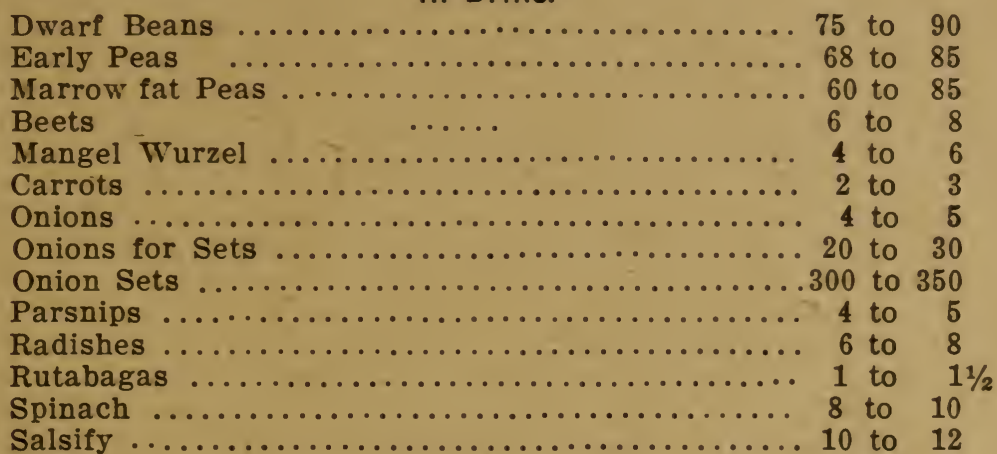

Table to Assist Farmers and Gardners in Making an Accurate Estimate of the Amount of Land in Different Fields Under Cultivation

10 rods by 1 rod equal 1 acre.

8 rods by 20 rods equal 1 acre.

5 rods by 32 rods equal 1 acre.

4 rods by - rods equal 1 acre.

5 yards by 968 yards euqal 1 acre.

10 yards by 484 yards equal 1 acre.

40 yards by 121 yards equal 1 acre.

209 feet by 209 feet equal 1 acre.

200 feet by 108.9 feet equal $1 / 2$ acre.

100 feet by 145.2 feet equal $1-3$ acre.

100 feet by 108.9 feet equal $1 / 4$ acre.

Weight of Different Manures to Apply to Different Crops Per Acre Potatoes, stable, 15 to 30 tons.

Mangel Wurzel, stable, 20 to 30 tons.

Carrots, stable, 12 to 20 tons.

Beans, stable, 12 to 30 tons.

Onions, stable, 25 to 40 tons.

Nitrate of Soda and Potash, $250 \mathrm{lbs}$.

Salt, 250 to 500 lbs.

Soot, 1,000 to $1,500 \mathrm{lbs}$.

Concentrated Fertilizers for garden or field, 500 to $800 \mathrm{lbs}$.

\section{Maturity Table.}

Beans, table use, 40 to 50 days.

Bets. table use, 50 to 70 days. days.

Cabbage, early for cutting, 70 to 80

Cabbage, late for cutting, 100 to 120 days.

Carrots, table use, 60 to 70 days.

Celery, table use, 120 to 140 days.

Sweet corn, table use, 65 to 80 days.
Cucumbers, table use, 45 to 60 days. Lettuce, table use, 40 to 50 days. Melons, table use, 65 to 90 days. Onions, for storage, 80 to 120 days. Peas, table use, 50 to 70 days.

Radishes, table use, 25 to 45 days. Tomatoes, table use, 90 to 100 days. Turnips, for storage, 65 to 90 days. 




\section{STARRETT'S SEED CATALOGUE}

1919

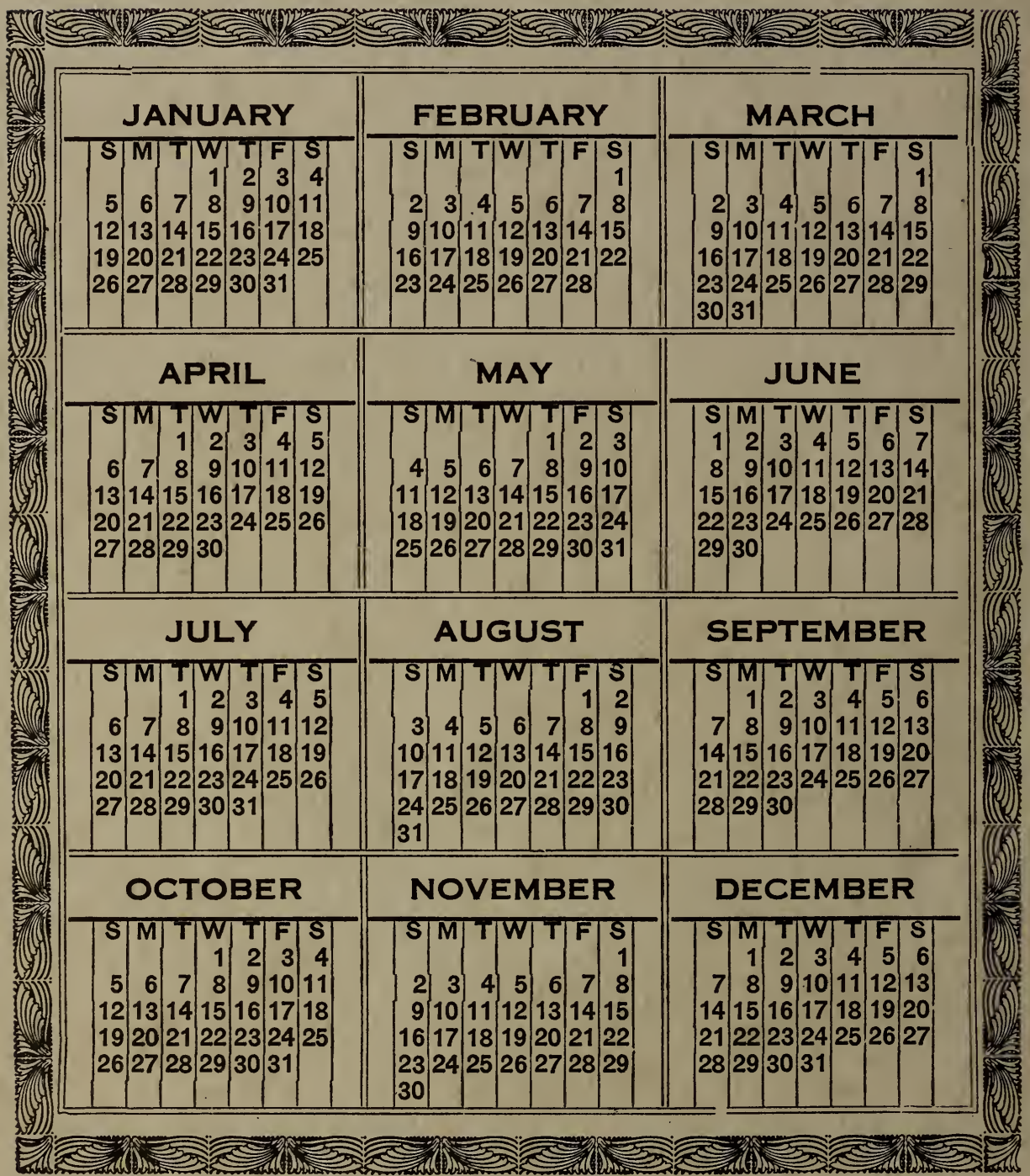

